\title{
Overview of the functional virulent genome of the coffee leaf rust pathogen Hemileia vastatrix with an emphasis on early stages of infection
}

\author{
Pedro Talhinhas ${ }^{1}$, Helena G. Azinheira ${ }^{1 *}$, Bruno Vieira ${ }^{2}$, Andreia Loureiro $^{1}$, Sílvia Tavares ${ }^{1}$, \\ Dora Batista ${ }^{1}$, Emmanuelle Morin ${ }^{3,4}$, Anne-Sophie Petitot ${ }^{5}$, Octávio S. Paulo ${ }^{2}$, Julie Poulain ${ }^{6}$, \\ Corinne Da Silva ${ }^{6}$, Sébastien Duplessis ${ }^{3,4}$, Maria do Céu Silva ${ }^{1}$ and Diana Fernandez ${ }^{5}$
}

${ }^{1}$ Centro de Investigação das Ferrugens do Cafeeiro/BioTrop/Instituto de Investigação Científica Tropical, Oeiras, Portugal

${ }^{2}$ Computational Biology and Population Genomics Group, Centro de Biologia Ambiental, Faculdade de Ciências da Universidade de Lisboa, Lisboa, Portugal

${ }^{3}$ Institut National de la Recherche Agronomique, Centre INRA Nancy Lorraine, UMR 1136 INRA/Université de Lorraine Interactions Arbres/Micro-organismes, Champenoux, France

${ }^{4}$ Université de Lorraine, UMR 1136 INRA/Université de Lorraine Interactions Arbres/Micro-organismes, Faculté des Sciences et Technologies, Vandoeuvre-lès-Nancy, France

${ }^{5}$ Institut de Recherche pour le Développement, UMR 186 IRD-Cirad-UM2 Résistance des Plantes aux Bioagresseurs, Montpellier, France

${ }^{6}$ Genoscope, Centre National de Séquençage, Commissariat à I'Energie Atomique, Institut de Génomique, Evry, France

\section{Edited by:}

David L. Joly, Université de Moncton, Canada

Reviewed by:

Hossein Borhan, Agriculture and Agri-Food Canada, Canada

Ralf Thomas Voegele, Universität

Hohenheim, Germany

\section{*Correspondence:}

Helena G. Azinheira, Centro de

Investigação das Ferrugens do

Cafeeiro, BioTrop, Instituto de

Investigação Científica Tropical,

Quinta do Marquês, 2784-505

Oeiras, Portugal

e-mail: hgazinheira@gmail.com
Hemileia vastatrix is the causal agent of coffee leaf rust, the most important disease of coffee Arabica. In this work, a 454-pyrosequencing transcriptome analysis of $H$. vastatrix germinating urediniospores $(\mathrm{gU})$ and appressoria (Ap) was performed and compared to previously published in planta haustoria-rich $(\mathrm{H})$ data. A total of 9234 transcripts were identified and annotated. Ca. 50\% of these transcripts showed no significant homology to international databases. Only 784 sequences were shared by the three conditions, and $75 \%$ were exclusive of either gU (2146), Ap (1479) or H (3270). Relative transcript abundance and RT-qPCR analyses for a selection of genes indicated a particularly active metabolism, translational activity and production of new structures in the appressoria and intense signaling, transport, secretory activity and cellular multiplication in the germinating urediniospores, suggesting the onset of a plant-fungus dialogue as early as at the germ tube stage. Gene expression related to the production of carbohydrate-active enzymes and accumulation of glycerol in germinating urediniospores and appressoria suggests that combined lytic and physical mechanisms are involved in appressoria-mediated penetration. Besides contributing to the characterization of molecular processes leading to appressoria-mediated infection by rust fungi, these results point toward the identification of new $H$. vastatrix candidate virulence factors, with 516 genes predicted to encode secreted proteins.

Keywords: appressorium, coffee leaf rust, germinating urediniospore, haustorium, pyrosequencing, transcriptome

\section{INTRODUCTION}

Rust diseases have been a long standing threat for centuries and have reshaped cultivation of crops and breeding strategies. Coffee leaf rust caused by Hemileia vastatrix Berk \& Broome is the major disease of Arabica cultivated coffees (Coffea arabica L.) (Silva et al., 2006). H. vastatrix is considered as one of the most primitive phylogenetic lineages of the Pucciniales (Aime, 2006; Silva et al., 2012) and has no alternate host known so far. Since the 19th century, when it caused suppression of the coffee cultivation in Sri Lanka, the disease gained a worldwide distribution, reaching nearly all regions of the world where coffee is grown with severe economical damages. Breeding and selection of coffee resistant genotypes to different fungal races from several parts of the world has been successful (Silva et al., 2006), but as a consequence of the high adaptive potential of the pathogen, the emergence of new rust pathotypes and the corresponding breakdown of resistance has been observed in many improved coffee varieties in several countries (Várzea and Marques, 2005; Diniz et al., 2012; Cressey,
2013). Thus, currently coffee leaf rust still stands as the major constraint to Arabica coffee production.

During infection of their hosts, rust fungi differentiate several specialized infection structures such as germtubes, appressoria, stomatal vesicles, infection hyphae, haustoria, and spore-forming cells. Until recently, most of the biological knowledge gained at the molecular level on rust fungi was derived from EST sequencing, mainly from ungerminated and germinating urediniospores, rust-infected tissues, isolated haustoria and some spore types at other stages of their complex life cycle (for a review see Duplessis et al., 2012; Fernandez et al., 2013). However, some differentiation stages are not sufficiently covered yet and lack description and information, such as appressoria formation (Fernandez et al., 2013). For instance, two studies conducted in Phakospora pachyrhizi and Puccinia triticina reported that a high proportion of genes of unknown functions were expressed at the appressorial stage (Hu et al., 2007; Stone et al., 2012). Appressoria may be also differentiated by other pathogenic fungi, enabling 
host cuticle penetration through physical and/or chemical mechanisms. Key features of these specialized structures include the production of an extracellular matrix for adhesion to the surface, the accumulation of molar concentrations of glycerol for generating turgor pressure and the differentiation of a penetration hypha (Deising et al., 2000). Appressoria differentiated from urediniospores typically form over host stomata, and a penetration hypha is subsequently formed at the base of the appressorium to invade the substomatic chamber. There are evidences that mechanical pressure (about $0.35 \mathrm{MPa}$ ) is exerted by the penetration hypha when penetrating the stoma (Terhune et al., 1993). This is considerably less than the pressure exerted by some fungi that penetrate directly through the cuticle, such as Magnaporthe oryzae or Colletotrichum spp. (Howard et al., 1991; Chen et al., 2004), but enough to distort stomatal guard cell lips (Terhune et al., 1993). Nevertheless, rust fungi must also possess machinery for lytic penetration of host cuticle and cell wall, since hyphae produced by germinating basidiospores are capable of direct penetration into host epidermal cells (Voegele et al., 2009).

Until very recently, no genomic resources were available for $H$. vastatrix. After several years of lagging behind other rust fungi on genomic research, Fernandez et al. (2012) reported on the 454-transcriptome sequencing of rust-infected coffee leaves. This study generated 22,774 contigs of which $30 \%$ were assigned to $H$. vastatrix. Analysis of these in planta expressed sequence tags (ESTs) revealed that the majority (60\%) had no homology in public genomic databases, representing potential coffee rust-specific genes. Nevertheless, $H$. vastatrix candidate effectors likely related to host infection and orthologous to other rust fungi, were identified among 382 predicted secreted proteins (Fernandez et al., 2012). Still, there is no knowledge of transcripts expressed at early stages of infection that could provide a more integrative scenario on the molecular mechanisms governing this pathosystem.

Complementing the knowledge gained into the in planta transcriptome of coffee rust, here we report on the in-depth transcriptome analysis of $H$. vastatrix by 454 -based RNA-Seq during urediniospore germination and appressorium formation, two early and key stages of infection. Comparison of these specific stages with infected leaves allows an integrative characterization of transcript expression profiles during the course of biotrophic growth and infection. In particular, the identification of genes related with appressorium formation leads to novel insights into a stage that has been poorly described at the molecular level.

\section{MATERIALS AND METHODS BIOLOGICAL MATERIAL, RNA ISOLATION AND cDNA SYNTHESIS}

Hemileia vastatrix isolate CIFC 178a (race XIV: genotype $v_{2} v_{3} v_{4} v_{5}$ ) was multiplied on its differential host plant (C. arabica accession CIFC H147/1, carrying the resistance factors $S_{H} 2$, $S_{H} 3, S_{H} 4$ and $\left.S_{H} 5\right)$. An in vitro method was used to produce germinating urediniospores and appressoria to ensure the generation of cDNA libraries with no contaminating plant sequences (Azinheira et al., 2001; Vieira et al., 2012). For the germinating urediniospores sample ( $\mathrm{gU}$ ), $19 \mathrm{mg}$ of spores were spread in sterile distilled water in Petri dishes and incubated for $18 \mathrm{~h}$ at $24^{\circ} \mathrm{C}$ under darkness. For the appressoria sample (Ap), $15 \mathrm{mg}$ of spores were spread over oil-collodion membranes (Vieira et al., 2012) in
Petri dishes, sprayed with water and incubated for $24 \mathrm{~h}$ at $24^{\circ} \mathrm{C}$ and $100 \%$ relative humidity, under darkness. For an accurate sample characterization, urediniospore germination and appressoria formation were quantified, showing that the germinating urediniospores sample ( $\mathrm{gU}$ ) comprised over $50 \%$ of germinating urediniospores. The appressoria sample (Ap) comprised over $60 \%$ of germinating urediniospores with appressoria. These are considered rather fair rates for $H$. vastatrix (Azinheira et al., 2001).

Samples gU and Ap were harvested, immediately frozen in liquid nitrogen and the RNA was isolated from each sample with the RNeasy Plant minikit (Qiagen, Hilden, Germany), including an in-solution DNase treatment following the manufacturer's instructions. RNA concentration and integrity were evaluated by spectrometry (Lambda EZ201, Perkin-Elmer, Waltham-MA, USA) and capillary electrophoresis (Bioanalyzer 2100, Agilent, Santa Clara-CA, USA) respectively. Following the SMARTer Pico PCR cDNA Synthesis Kit (Clontech, Saint-Germain-enLaye, France) protocol, cDNA were synthesized from $1 \mu \mathrm{g}$ total RNA using SMARTScribe Reverse Transcriptase (Clontech) and amplified using Advantage 2 Polymerase (Clontech). cDNA fragments, which ranged between 500 and $3000 \mathrm{bp}$, were purified with the NucleoSpin Extract II kit (Macherey-Nagel, Düren, Germany) and their quality and concentration were evaluated by electrophoresis.

\section{PYROSEOUENCING AND ASSEMBLY OF 454 READS}

For each sample, $20 \mu \mathrm{g}$ cDNA was used for 454-pyrosequencing run on half of a picotitre plate on a Genome Sequencer FLX System using long-read GS FLX Titanium chemistry (Roche; www.454.com) at the Genoscope (Centre National de Séquençage, Evry, France; www.genoscope.cns.fr) following standard procedures recommended by Roche.

Raw sequences obtained for $\mathrm{gU}$ and Ap samples were assembled into contigs using Newbler 2.5 (Roche) with default parameters. For comparative purposes, the MIRA 3.2 assembler (http://sourceforge.net/apps/mediawiki/mira-assembler) was also employed. The relative abundance $(\mathrm{Ra})$ of transcripts was calculated as the ratio between the number of 454 reads per contig and the length of the assembled contig (Vega-Arreguín et al., 2009).

\section{BIOINFORMATIC ANALYSIS OF TRANSCRIPTS}

As previously described (Fernandez et al., 2012), sequence homology searches were performed against several databases: the NCBI non-redundant (nr) nucleotide and protein databases (www.ncbi.nlm.nih.gov), the genome sequences of Melampsora larici-populina and Puccinia spp. (Cantu et al., 2011; Duplessis et al., 2011a; www.jgi.doe.gov and www.broadinstitute.org, respectively); the euKaryotic Orthologous Group (KOG) database (Tatusov, 2003); the Pathogen-Host Interaction (PHIbase v3.2) reference database (Winnenburg et al., 2007; www. phi-base.org); the Phytopathogenic Fungi and Oomycete EST Database (COGEME v1.6; Soanes and Talbot, 2006); and a Pucciniales EST database (168,199 ESTs retrieved from GenBank in November 2012 - unchanged number as of December 2013). Besides these, 16,831 transcripts from the M.larici-populina 
frozen gene catalog (http://genome.jgi-psf.org/Mellp1/Mellp1. download.ftp.html) and 20,567 (P. graminis f. sp. tritici) and 11,638 (P. triticina) from the Puccinia spp. transcript catalogue (http://www.broadinstitute.org/annotation/genome/puccinia_ group/MultiDownloads.html) were also considered. Homology searches were performed using BLAST algorithms (Altschul et al., 1997) with a cut-off criterion $\left(e\right.$-value $\left.<10^{-5}\right)$. For each search against a given database, only the best hit was considered. The assignment of 454-contig sequences into KOG functional categories was obtained using Reverse psi-BLAST (RPSBLAST; Altschul et al., 1997) against the KOG database.

Open reading frames (ORFs) were predicted with the translation tool getorf from the European Molecular Biology Open Software Suite (EMBOSS; http://emboss.bioinformatics. nl/cgi-bin/emboss/getorf) using default parameters. ORFs below 18 amino acids were not considered. A secretome bioinformatics pipeline was employed to define a tentative set of secreted proteins encoded by $H$. vastatrix transcripts, using SignalP v4.0 (Petersen et al., 2011), TargetP v1.1 (Emanuelsson et al., 2000) and TMHMM v2.0 (Krogh et al., 2001).

The catalytic and carbohydrate-binding modules (or functional domains) of enzymes that degrade, modify, or create glycosidic bonds (carbohydrate-active enzymes-CAZymes) was investigated by blastp comparison of predicted polypeptides to the CAZymes database (www.cazy.org; Cantarel et al., 2009) and to the CAZymes from M. larici-populina and P. graminis $\mathrm{f}$. $\mathrm{sp}$. tritici (Duplessis et al., 2011a). Similarly, proteins involved in membrane transport were investigated by blastp searches against predicted polypeptides in the Transporter Classification Database (www.tcdb.org; Saier et al., 2006, 2009).

Contigs from $\mathrm{gU}$ and Ap samples, as well as those predicted as fungal from a 21 day infected-coffee leaf sample (sample H; Fernandez et al., 2012), were compared using a best reciprocal BLAST hit approach with BioEdit 7.0.4.1 (Hall, 1999). Pairs of contigs with an $e$-value lower than $10^{-30}$ were considered as representing the same transcript and assembled. Ra values were calculated for each transcript present in more than one library, and these values were compared across the libraries in order to evaluate variations in expression levels. For such, $\tau$ values were calculated for each gene based on the normalized Ra values, in order to account for differences in library sizes. The expression specificity index $(\tau)$ is defined as $\tau=\frac{\sum_{i=1}^{n}\left(1-x_{i}\right)}{n-1}$, where $\mathrm{n}$ is the number of tissues and $x_{i}$ is the expression profile component normalized by the maximal component value (Yanai et al., 2005). The genes with the most stable expression across the three libraries were selected (105 genes with $\tau$ values below 0.25 ). Average Ra values were calculated among these genes for each library ( 0.02684 for $\mathrm{gU}, 0.03158$ for Ap and 0.03039 for $\mathrm{H}$ ) and $\mathrm{Ra}$ values for each contig in each library were normalized to the $\mathrm{gU}$ sample, following the strategy described by Ekblom et al. (2010) based on the guidelines provided by Mank et al. (2008).

\section{RT-qPCR}

Germinating urediniospores (gU) and appressoria (Ap) samples for $H$. vastatrix isolate $178 \mathrm{a}$ were obtained as described above. In planta time course samples were collected at $18 \mathrm{~h}$ (mostly containing appressoria) and 1, 2, 3, 7, 14, and 21 days after inoculation for the compatible interaction between isolate 178a and the C. arabica genotype H147/1, as previously described (Diniz et al., 2012; Vieira et al., 2012). Fungal germination, appressoria formation and the differentiation of infection structures in planta were monitored by light microscopy as previously described (Vieira et al., 2012). RNA extraction, cDNA synthesis and RT-qPCR experiments were performed as previously described (Vieira et al., 2012), using Hv00099, 40 S ribosomal protein and glyceraldehyde-3-phosphate dehydrogenase as reference genes (Vieira et al., 2011) and ungerminated urediniospores as the control sample. A set of 43 genes was selected for RTqPCR analysis based on RNA-Seq expression profiles and assigned functions. Primers (Supplementary Data 1) were designed as previously described (Vieira et al., 2012).

\section{RESULTS AND DISCUSSION 454-PYROSEOUENCING DATA FOR GERMINATING UREDINIOSPORES AND APPRESSORIA SAMPLES}

Given that different 454-pyrosequencing data assemblers are available and are known to generate diverse results (Kumar and Blaxter, 2010), MIRA 3.2 and Newbler 2.5 were compared in this study. In general, MIRA produced shorter and more numerous contigs. The overall homology scores of contigs to a Pucciniales EST database was better for the Newbler assembly (data not shown), suggesting a better quality of the assemblage which led us to use Newbler assembly in this study.

For samples gU and Ap (Table 1), a total of 455,807 sequence reads $(113,404,366$ nucleotides) was generated and assembled into 9108 contigs ( 4267 for $\mathrm{gU}$ and 3626 for Ap), with ca. 24\% sequences remaining as either too short/low quality sequences (7\%) or singletons (17\%). Among those, 1214 contigs (13\%) were $<100 \mathrm{bp}$ and not further considered in the analysis. The remaining 7894 contigs (Supplementary Data 2) had a mean length of $656 \mathrm{bp}$ (Table 1), with $16 \%$ contigs larger than $1 \mathrm{~kb}(3.7 \%$ larger than $2 \mathrm{~kb}$ ). Mean number of reads per contig was 41.0 , with $11 \%$ contigs over 50 reads. Mean relative abundance $(\mathrm{Ra})$ was 0.1153 , with $18 \%$ contigs (1424) representing transcripts with a medium to high rate of expression $(\mathrm{Ra}>0.05)$.

In the absence of genomic information for $H$. vastatrix, contigs were compared to sequences deposited in databases (summary in Table 2 and results by contig listed in Supplementary Data 2), and $54 \%$ contigs had homology (e-value $<10^{-5}$ ) to the NCBI nr nucleotide database using blastn (Supplementary Data 2, columns G-I).

A total of 13,951 sequences obtained from the 21-days $H$. vastatrix infected-coffee leaf samples (H library) and previously predicted as of plant origin (Fernandez et al., 2012) were compared to the $\mathrm{gU}+\mathrm{Ap}$ sequences, from which 22 showed an homology $e$-value below $10^{-60}$ (19 of which had $e$-value of 0.0 ; Supplementary Data 3 ). This analysis showed that only $0.1 \%$ of the sequences predicted as of plant origin (Fernandez et al., 2012) were wrongly assigned to this class. Similarly, among 2060 contigs previously classified as "not attributed/not resolved," 28 had homology to gU+Ap sequences with an $e$-value below $10^{-60}$ (21 of which had $e$-value of 0.0 ). These 50 contigs (evalue $<10^{-60}$ ) were incorporated in the present study, together with the 4415 fungal contigs initially identified in the $\mathrm{H}$ library, 
summing a total of $4465 \mathrm{H}$ contigs (Fernandez et al., 2012) to our dataset.

\section{COMPARISON TO THE IN PLANTA EXPRESSED FUNGAL SEQUENCES}

A best reciprocal BLAST strategy was used to compare the contigs from both $\mathrm{gU}$ and Ap libraries, as well as the fungal contigs from the H library (Fernandez et al., 2012). This enabled the identification and re-assembly of 784 sequences shared by the three libraries, 1145 shared only by gU and Ap, 219 by Ap and $\mathrm{H}$ and 192 by gU and $\mathrm{H}$ (Figure 1 and Supplementary Data 4, columns

\section{Table 1 | Descriptive statistics for Hemileia vastatrix 454 pyrosequenced cDNA libraries of germinated urediniospores $(\mathrm{gU})$ and} appressoria (Ap).

\begin{tabular}{lcc}
\hline Library & gU & Ap \\
\hline Number of bases & 67773266 & 45631100 \\
Number of sequences & 269199 & 186608 \\
Mean size of reads (bp) & 251.8 & 244.5 \\
Number of contigs & 4267 & 3626 \\
Mean size of contigs (bp) & 676 & 632 \\
Size of contigs (bp)* & $188 / 546 / 1293 /$ & $192 / 530 / 1139 /$ \\
& 3754 & 4860 \\
Mean number of reads & 48.5 & 32.2 \\
per contig & & $4 / 9 / 52 / 2077$ \\
Reads per contig* & $4 / 10 / 63 / 3326$ & 0.0797 \\
Mean relative abundance & 0.1456 & \\
(Ra) & & $0.0085 / 0.0187 /$ \\
Relative abundance (Ra)* & $0.0087 / 0.0190 /$ & $0.0777 / 14.41$ \\
\hline
\end{tabular}

* Values correspond to 10/50/90/100 percentiles.
B-D). The remaining 6894 sequences (75\%) are exclusive of each library. Altogether, 9234 unique $H$. vastatrix sequences were identified, which represents $>50 \%$ of the total number of genes predicted from the genomes of M. larici-populina (16,399 genes) and P. graminis f. sp. tritici (17,773 genes) (Duplessis et al., 2011a). In order to further ascertain a measure of the genome coverage obtained in this study, we compared each of the three libraries ( $\mathrm{gU}, \mathrm{Ap}$, and $\mathrm{H}$ ) separately, along with the total set of 9234 sequences, against the FUNYBASE database containing 246 families of single-copy orthologs obtained from 21 genomes (core

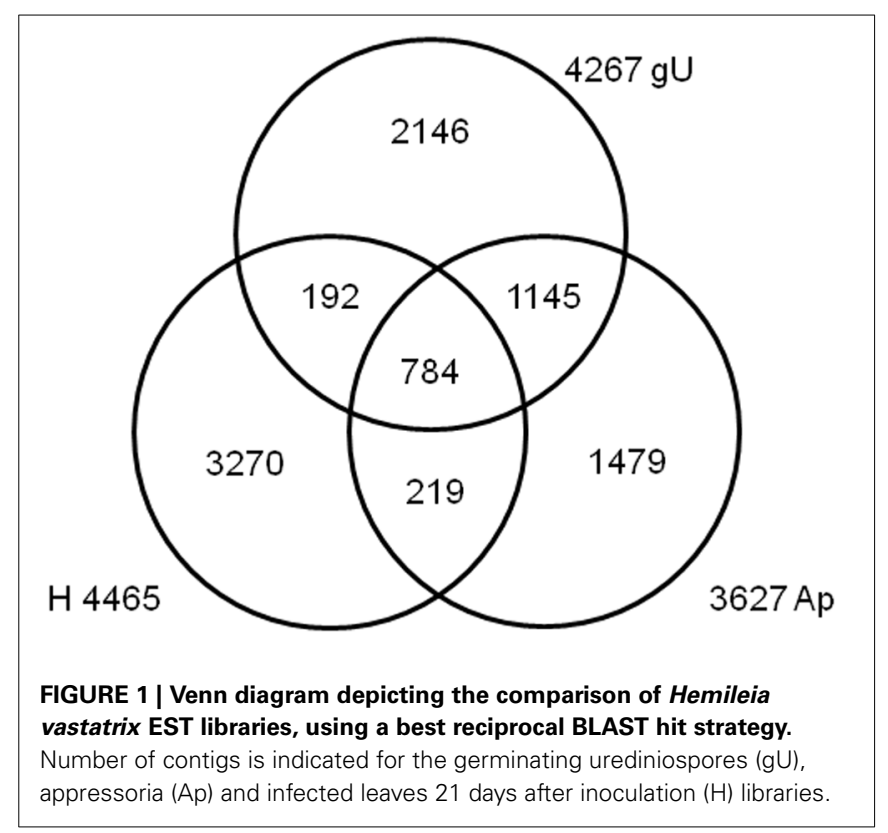

Table 2 | Hemileia vastatrix transcript homology in databases and KOG functional categories classification.

\begin{tabular}{|c|c|c|c|c|c|c|}
\hline Library & $\mathbf{g U}$ & Ap & Total & $\%$ of all gU contigs & $\%$ of all Ap contigs & $\%$ of all contigs \\
\hline NCBI nr_blastn & 2119 & 2126 & 4245 & 49.66 & 58.62 & 53.78 \\
\hline Mlp genome_tblastx & 2356 & 2159 & 4515 & 55.21 & 59.53 & 57.20 \\
\hline Pgt_genome_tblastx & 2294 & 2099 & 4393 & 53.76 & 57.87 & 55.65 \\
\hline Pt_genome_tblastx & 2410 & 2171 & 4581 & 56.48 & 59.86 & 58.03 \\
\hline Pst_genome_tblastx & 2408 & 2159 & 4567 & 56.43 & 59.53 & 57.85 \\
\hline EST_Pucciniales_tblastx & 2507 & 2334 & 4841 & 58.75 & 64.35 & 61.33 \\
\hline SwissProt_blastx & 1301 & 1362 & 2663 & 30.49 & 37.55 & 33.73 \\
\hline PHIbase_tblastx & 482 & 444 & 926 & 11.30 & 12.24 & 11.73 \\
\hline COGEME_tblastx & 2016 & 2042 & 4058 & 47.25 & 56.30 & 51.41 \\
\hline KOG & 1691 & 1690 & 3381 & 39.63 & 46.59 & 42.83 \\
\hline Posttranslational modification, protein turnover, chaperones & & & & 12.5 & 13.6 & \\
\hline Translation, ribosomal structure and biogenesis & & & & 12.4 & 19.7 & \\
\hline Intracellular trafficking, secretion, and vesicular transport & & & & 8.2 & 5.7 & \\
\hline Energy production and conversion & & & & 7.9 & 9.1 & \\
\hline Signal transduction mechanisms & & & & 7.5 & 6.3 & \\
\hline Lipid transport and metabolism & & & & 5.7 & 6.4 & \\
\hline
\end{tabular}

Summary of the number and percentage of hits in homology searches of the $H$. vastatrix germinated urediniospores (gU) and appressoria (Ap) contig libraries against the NCBI nr database (NCBI nr_blastn), rust genomic and transcriptomic databases (Mlp_genome_tblastx, Pgt_genome_tblastx, Pt_genome_tblastx, Pst_genome_tblastx, EST_Pucciniales_tblastx), the SwissProt database (SwissProt_blastx) and functional databases (PHIbase_tblastx, COGEME_tblastx, KOG). 
fungal genes) (Marthey et al., 2008). Each individual library contained only about half of the 246 genes (39\% in $\mathrm{H}$ and $55 \%$ both in $\mathrm{Ap}$ and gU; data not shown), but the $\mathrm{gU}+\mathrm{Ap}+\mathrm{H}$ library included $174(71 \%)$ of those core genes (Supplementary Data 4, columns BN-BP). These results indicate that the 9234 unique $H$. vastatrix transcripts provide a significant coverage of the $H$. vastatrix functional genome.

According to their RNA-Seq expression values and assigned functions, the expression profiles of a set of 43 genes was analyzed by RT-qPCR along the time course of a compatible interaction (Table 3).

\section{GENE FUNCTION}

Over $72 \%$ of the $9234 \mathrm{H}$. vastatrix transcripts had no specific KOG category assigned (No hits, "Function unknown" or "General function prediction only"; Table 4 and Supplementary Data 4, columns BK-BM). Within the remaining transcripts, the most represented KOG categories are "Translation, ribosomal structure and biogenesis" (14\%) and "Post-translational modification, protein turnover, chaperones" (12\%), while other nine categories represent 5-8\% each.

A total of 4040 transcripts (44\% of total) presented homologies against the NCBI non-redundant nucleotide database (Supplementary Data 4, columns V-X). A similar value (45\%) was obtained by comparison (tblastx) with the Pucciniales EST database (Supplementary Data 4, columns AY-BA), with the most frequent organisms being $M$. larici-populina, P. triticina, P. graminis f. sp. tritici and P. pachyrhizi in similar proportions to those reported for the $\mathrm{gU}$ and Ap libraries (Supplementary Data 4, columns Y-AN). A total of 2992 transcripts (32\%) have homology to all available rust genome sequences, suggesting that the corresponding genes are conserved among the Pucciniales. Only 16 transcripts showed homology to $P$. graminis f. sp. tritici or P. triticina mitochondrial sequences (Supplementary Data 4, columns AS-AX). A total of 141 and 148 transcripts did not show homology to M. larici-populina and P. striiformis gene models respectively, although showing significant homology to their genome sequences, which could indicate actual genes that were not predicted by automatic annotations in the corresponding genomes (Supplementary Data 4, columns $\mathrm{AB}-\mathrm{AE}$ and $\mathrm{AO}-\mathrm{AR}$ ). Interestingly, 4707 transcripts ( $51 \%$ of total) showed no homology to the rust genes identified in genome sequences or EST databases (at a cut off $e$-value of $10^{-10}$ ), suggesting they may correspond to highly divergent or specific $H$. vastatrix genes. In fact, among these, only $3.2 \%$ have a specific KOG category assigned, with an overrepresentation of categories involved in cellular structure, nucleic acid activity and signaling ("Cytoskeleton," "RNA processing and modification," "Transcription" and "Signal transduction mechanisms").

A total of 3573 transcripts showed homology to annotated fungal genes listed in the COGEME database (Supplementary Data 4, columns BH-BJ), Ustilago maydis (21\%), Giberella spp. (13\%), and $M$. oryzae (13\%) being the most represented species. Further, 588 transcripts showed homology to fungal pathogenicity-related genes listed in the PHI database (Supplementary Data 4, columns BE-BG; $94 \%$ of which also have homologues in the COGEME database), mostly from M. oryzae (19\%), Candida albicans (18\%), and Cryptococcus neoformans (14\%). About $70 \%$ of these 588 transcripts had specific KOG categories assigned, with categories such as "Cell cycle control, cell division, chromosome partitioning," "Secondary metabolites biosynthesis, transport and catabolism" and "Signal transduction mechanisms" overrepresented as compared to KOG categories assigned to all genes (Table 4).

For each transcript, the size of the predicted polypeptide was compared to the size of the corresponding polypeptide in the P. graminis f. sp. tritici genome. Among the 3686 hits to the $P$. graminis f. sp. tritici genome, $24 \%$ were $>90 \%$ the length of their orthologs ( $46 \%$ proteins were $>50 \%$ size; Supplementary Data 4 , columns BQ-BS).

As $H$. vastatrix 454 cDNA libraries were not normalized, the number of reads contained in each contig can be considered a relative expression level of each gene. For each contig, the number of reads was divided by the length of the contig, resulting in a Relative Abundance ( $\mathrm{Ra}$ ) index (Supplementary Data 4, columns G-O). Comparison among contigs from different libraries required a normalization step in order to account for differences in library sizes (Supplementary Data 4, columns P-S). Based on the comparative analysis of the expression levels identified in each library, nine different expression profiles were defined (Supplementary Data 4, column U). The most frequent profiles observed reflect the fact that $75 \%$ of contigs are exclusive of a single library, with $87 \%$ of the 9234 predicted transcripts presenting profiles 1 , 2, or 3 (Table 5 , row 4 ).

The analysis of relative abundance values according to the KOG category of each gene (Table 5) suggests a particularly active metabolism, translational activity and production of new structures in the Ap sample and both intense signaling and secretory activity and cellular multiplication in germinating urediniospores. In the $\mathrm{H}$ sample, over-represented KOG categories suggest intense signaling and nutrient uptake from the host to the fungus, as previously pointed out (Fernandez et al., 2012).

\section{SECRETED PROTEINS}

A total of 467 putative secreted proteins were predicted with a secretion prediction pipeline composed of the SignalP, TargetP and TMHMM programmes (Supplementary Data 4, columns BT to CI for SignalP, CJ to CO for TargetP, CP to CS for TMHMM, CT for TMHMM vs. SignalP comparison and CU for final secretion prediction score). Besides these, other transcripts showing high homology $\left(e\right.$-value $<10^{-30}$ ) to the M. larici-populina or the P. graminis f. sp. tritici predicted secreted proteins (Duplessis et al., 2011a) were also selected (Supplementary Data 4, column $\mathrm{CV}$ ) even if not detected by the pipeline. Since these sequences were shorter than their orthologs, the signal peptide may be lacking from sequence. From this list of 516 transcript encoding putative secreted proteins, 87 and $70 \%$ entries presented less than 300 amino acids, and 200 amino acids, respectively (Supplementary Data 4, column BR). Also, 82 of these translated gene sequences are highly enriched in cysteine residues (5-15\% of all amino acids; Supplementary Data 4, column CW), the vast majority of which (78) is less than 200 aa, similar to what was reported for M. larici-populina small secreted proteins (Hacquard et al., 2012). Nearly $60 \%$ of these 82 sequences contain 


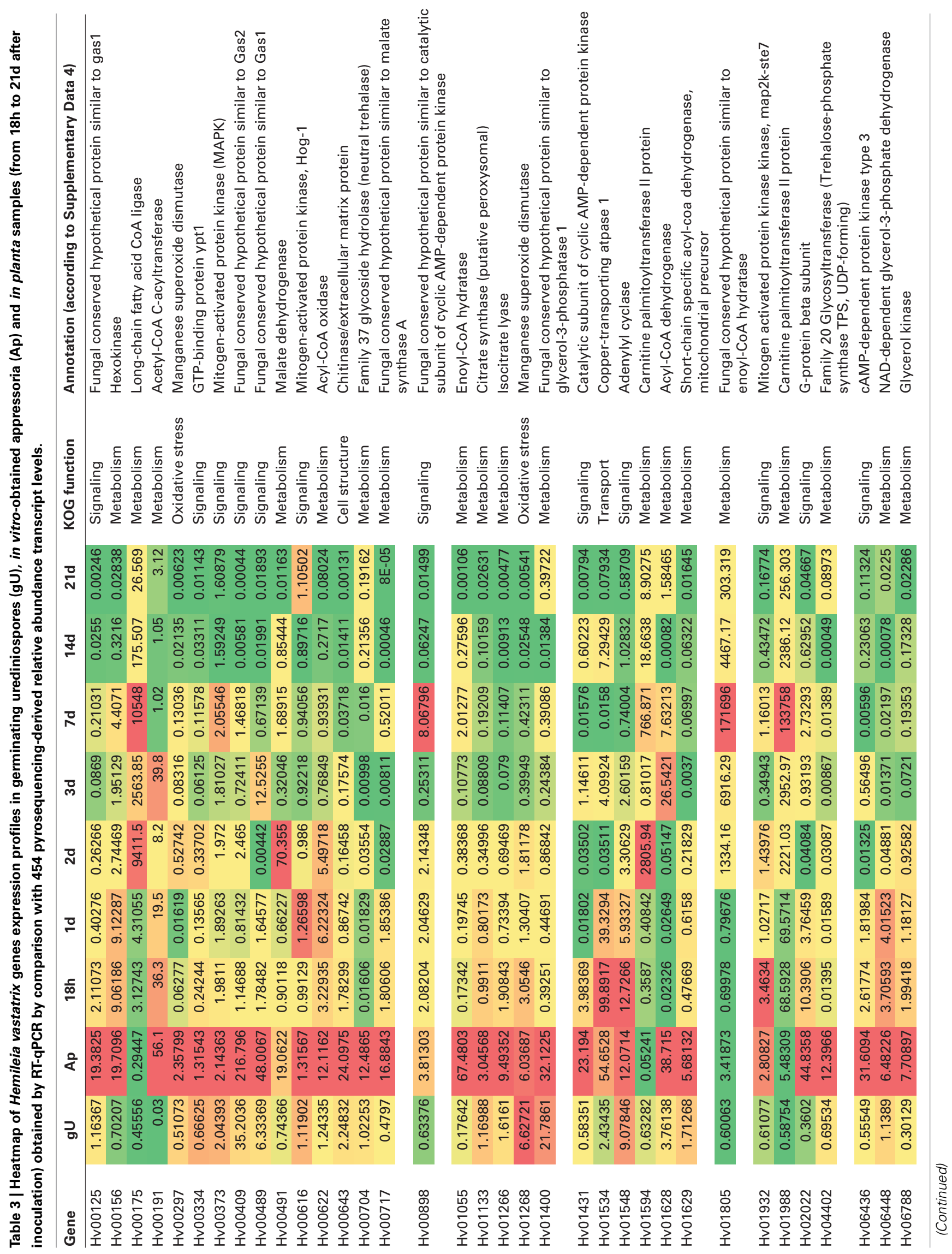




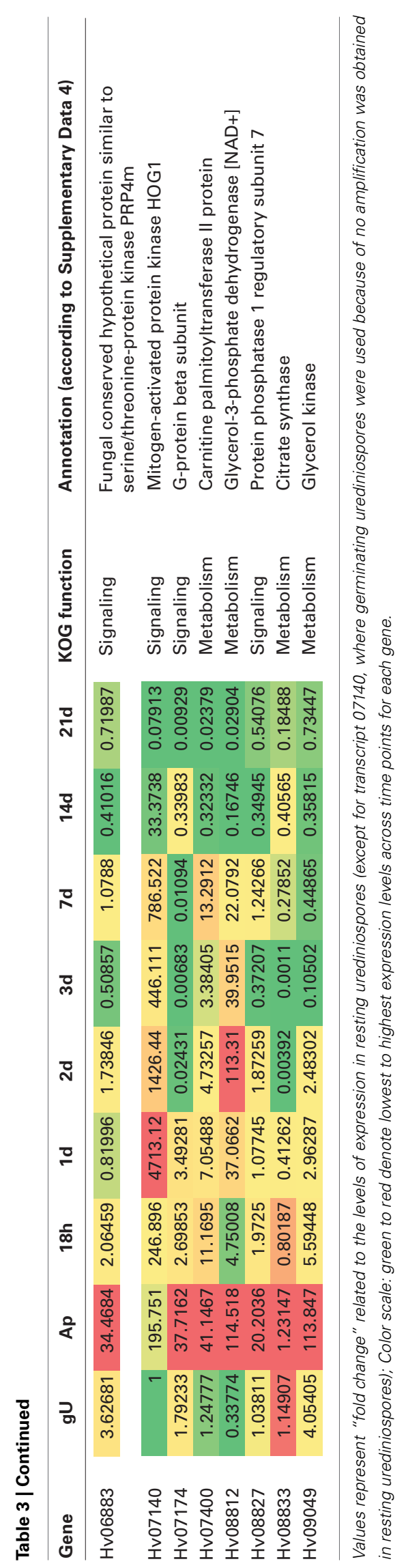

a $[$ YFW] $\times$ C motif (Supplementary Data 4, column CX), while only $20 \%$ of the remaining 434 sequences ( $<5 \%$ cysteines) possess that motif. An overrepresentation of this particular motif was similarly observed for the small secreted proteins of the poplar rust fungus (Hacquard et al., 2012). Secreted proteins transcripts tend to present high relative expression values: while they represent $5.6 \%$ of all 9234 genes in this study, they represent $12-14 \%$ of genes with $\mathrm{Ra}>1$ (Table 5). Moreover, the sum of all Ra values for predicted secreted proteins is higher in $\mathrm{gU}$ than in Ap or $\mathrm{H}$, although more genes were identified in $\mathrm{H}$ (Figure 2). In addition, 46 of these genes encoding predicted secreted proteins present homology to genes in the PHI database (Supplementary Data 5) whose mutants in various fungi exhibit either loss of pathogenicity or reduced virulence phenotype, 21 of which were up-regulated in the gU library, 13 in Ap and 11 in $\mathrm{H}$ according to Ra values.

Four transcripts (00303, 00357, 01043, and 04304) encoding predicted secreted proteins are orthologous of the rust transferred protein (RTP1) genes (Pretsch et al., 2013) from U. fabae, M. occidentalis or M. medusae f. sp. deltoidis (Supplementary Data 6). Orthologs of these four genes were also identified in M. laricipopulina and Puccinia spp. genomes (Supplementary Data 7) and the overall similarity among genes is quite low (Supplementary Data 6, columns Z-AD). Three of these transcripts were previously identified in H. vastatrix transcripts (Fernandez et al., 2012; see Supplementary Data 6). Transcript 04304 was exclusively detected in the H library (Supplementary Data 6), corroborating the observations by Vieira et al. (2012) and the expression profile of RTP1 in $U$. fabae (Kemen et al., 2005). Transcript 01043 was detected in $\mathrm{Ap}$ and $\mathrm{H}$, and transcripts 00303 and 00357 were identified in the three libraries. Different expression profiles could be observed, transcript 00303 being highly expressed in Ap, transcript 01043 more expressed in Ap and $\mathrm{H}$ and transcript 00357 showing similar Ra values across the three libraries. $H$. vastatrix RTP1 orthologs show distinct expression profiles for the different members of this single gene family. Such an observation confirms the very dynamic and specific transcriptional process at the gene family level that was reported for gene families encoding small secreted proteins of M. larici-populina during time course infection of poplar leaves (Duplessis et al., 2011b).

Some $H$. vastatrix transcripts are orthologous of haustorially expressed secreted proteins (HESP) identified in Melampsora lini (Dodds et al., 2006; Barrett et al., 2009) (Supplementary Data 7). Among these, HESP-178 is orthologous to the transcripts 01506 and 04456 , detected respectively in $\mathrm{gU}$ and $\mathrm{Ap}$, and in $\mathrm{H}$ libraries (Supplementary Data 8). HESP-379 is orthologous to transcript 00258, which was identified in the three libraries at decreasing levels of expression along the differentiation stages, confirming previous observations (Fernandez et al., 2012). HESP767 is orthologous to transcript 09298 only identified in library Ap. No homology was detected to Melampsora spp. Avr genes (Dodds et al., 2004), presumably because of their poor conservation across the Pucciniales (Catanzariti et al., 2006; Duplessis et al., 2011a).

Several transcripts present homology to genes involved in the alleviation of oxidative stress caused by ROS. By instance, two transcripts (00297 and 01268) with homology to Mn-type 
Table 4 | Distribution of Hemileia vastatrix genes by KOG categories considering all genes and different groups of genes according to their homology or predicted function.

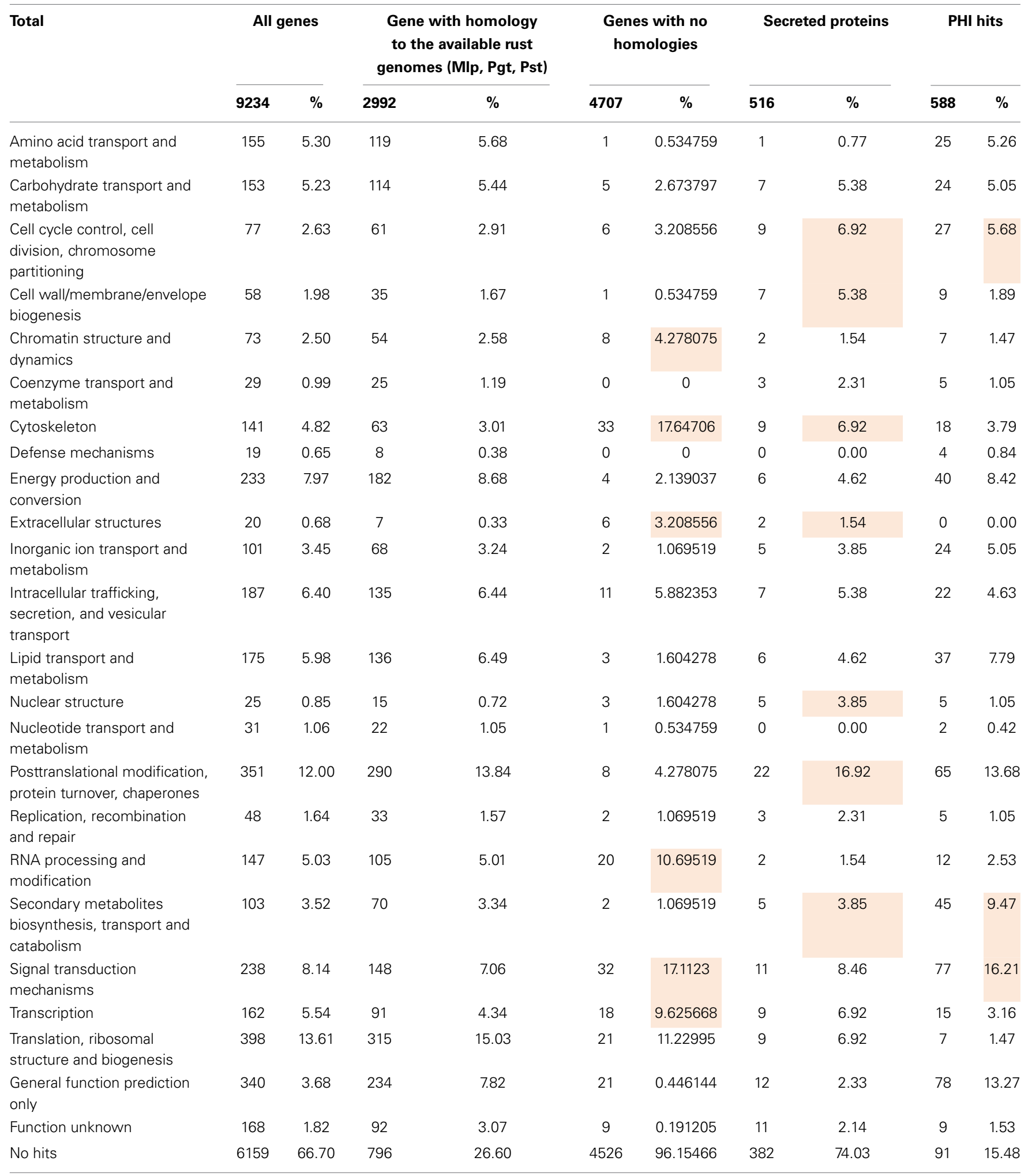

For the non-specific categories ("No hits," "Function unknown" or "General function prediction only"), \% refers to the total number of genes. For the remaining categories, \% refers to the total number of genes with specific KOG categories assigned; highlighted cells correspond to information that is referred to in the article. 


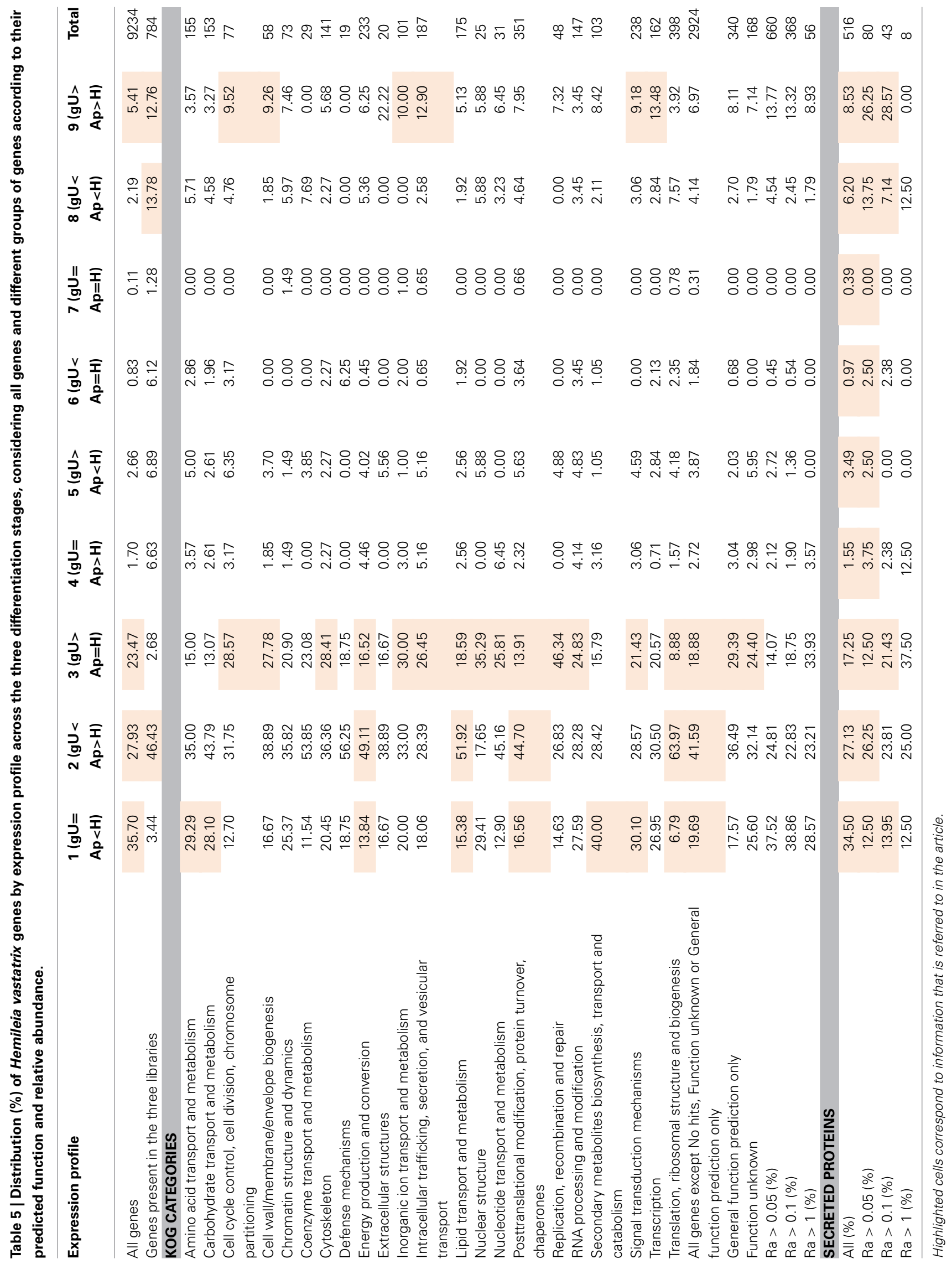




\begin{tabular}{|c|c|c|c|c|c|c|}
\hline & \multicolumn{3}{|c|}{ Number of genes } & \multicolumn{3}{|c|}{ Relative abundance } \\
\hline & $\mathrm{gU}$ & Ap & $\mathrm{H}$ & $\mathrm{gU}$ & Ap & $\mathrm{H}$ \\
\hline Secreted proteins & 249 & 242 & 301 & 78.22 & 29.53 & 25.56 \\
\hline$<200 a a$ & 79 & 61 & 129 & 31.8625 & 11.2911 & 14.0697 \\
\hline$>5 \%$ Cysteines & 27 & 29 & 48 & 8.1476 & 1.7498 & 3.7998 \\
\hline [YFW] $\times C$ motif containing & 54 & 61 & 78 & 6.3661 & 11.7250 & 1.5273 \\
\hline CAZymes & 89 & 90 & 57 & 6.809 & 3.358 & 1.225 \\
\hline Carbohydrate Esterase & 9 & 12 & 11 & 0.4511 & 0.3405 & 0.2845 \\
\hline Carbohydrate-Binding Module & 2 & 5 & 2 & 0.0578 & 0.1237 & 0.0663 \\
\hline Glycoside Hydrolase & 43 & 40 & 32 & 2.8917 & 1.8615 & 0.6192 \\
\hline Glycosyltransferase & 32 & 30 & 12 & 0.3682 & 0.4281 & 0.1109 \\
\hline Transporters & 138 & 127 & 98 & 6.590 & 2.994 & 2.539 \\
\hline Metabolic pathways & 349 & 395 & 305 & 14.320 & 8.995 & 22.990 \\
\hline Pathogenicity genes & 286 & 292 & 186 & 6.6649 & 5.4458 & 4.9834 \\
\hline Signal transduction mechanisms & 38 & 40 & 27 & 0.551 & 0.5401 & 0.6832 \\
\hline Posttranslational modification, protein turnover, chaperones & 22 & 28 & 19 & 0.2415 & 0.4502 & 0.5434 \\
\hline Energy production and conversion & 18 & 26 & 18 & 0.2759 & 0.4666 & 0.3882 \\
\hline Lipid transport and metabolism & 19 & 24 & 13 & 0.2290 & 0.3573 & 0.1802 \\
\hline Secondary metabolites biosynthesis, transport and catabolism & 7 & 16 & 10 & 0.0575 & 0.2008 & 1.0602 \\
\hline \multicolumn{7}{|l|}{ KOG categories } \\
\hline Amino acid transport and metabolism & 67 & 85 & 82 & 0.6158 & 1.0915 & 7.0027 \\
\hline Carbohydrate transport and metabolism & 65 & 88 & 74 & 0.6730 & 1.3595 & 1.3705 \\
\hline Cell cycle control, cell division, chromosome partitioning & 51 & 40 & 39 & 0.9816 & 0.6809 & 0.5840 \\
\hline Cell wall/membrane/envelope biogenesis & 33 & 31 & 21 & 0.8085 & 0.8442 & 1.2180 \\
\hline Chromatin structure and dynamics & 43 & 38 & 39 & 1.7490 & 7.0806 & 3.3650 \\
\hline Coenzyme transport and metabolism & 17 & 18 & 11 & 0.1554 & 0.3872 & 0.1487 \\
\hline Cytoskeleton & 78 & 67 & 63 & 2.8448 & 7.7092 & 5.9115 \\
\hline Defense mechanisms & 8 & 12 & 4 & 0.0569 & 0.1171 & 0.1062 \\
\hline Energy production and conversion & 130 & 152 & 98 & 1.9564 & 3.0311 & 1.8325 \\
\hline Extracellular structures & 12 & 12 & 5 & 4.2132 & 2.1092 & 0.0562 \\
\hline Inorganic ion transport and metabolism & 61 & 50 & 33 & 2.9121 & 1.6024 & 1.0367 \\
\hline Intracellular trafficking, secretion, and vesicular transport & 139 & 97 & 75 & 1.8922 & 1.6718 & 1.2310 \\
\hline Lipid transport and metabolism & 98 & 112 & 56 & 1.1721 & 2.0621 & 0.7688 \\
\hline Nuclear structure & 17 & 10 & 13 & 0.3586 & 1.9497 & 0.1668 \\
\hline Nucleotide transport and metabolism & 19 & 19 & 9 & 0.1962 & 0.3500 & 0.2885 \\
\hline Posttranslational modification, protein turnover, chaperones & 204 & 228 & 159 & 3.0086 & 5.1990 & 3.0526 \\
\hline Replication, recombination and repair & 35 & 18 & 18 & 0.3704 & 0.2931 & 0.2156 \\
\hline RNA processing and modification & 84 & 64 & 74 & 1.0546 & 1.1414 & 0.2150 \\
\hline Secondary metabolites biosynthesis, transport and catabolism & 41 & 46 & 48 & 2.5150 & 1.0394 & 9.7508 \\
\hline Signal transduction mechanisms & 132 & 112 & 111 & 4.0205 & 8.0394 & 6.7880 \\
\hline Transcription & 98 & 77 & 68 & 1.9524 & 1.7127 & 1.2772 \\
\hline Translation, ribosomal structure and biogenesis & 212 & 325 & 151 & 4.4119 & 11.4528 & 4.9655 \\
\hline General function prediction only & 201 & 171 & 131 & 3.1023 & 5.5329 & 10.8636 \\
\hline Function unknown & 101 & 77 & 75 & 2.2658 & 1.4814 & 1.5117 \\
\hline No hits & 2524 & 1846 & 3166 & 311.775 & 186.672 & 304.552 \\
\hline All genes & 4267 & 3626 & 4465 & 350.37 & 245.69 & 355.71 \\
\hline \multicolumn{2}{|c|}{$\begin{array}{l}\text { FIGURE } 2 \text { | Heatmaps of the number of genes and sum of their relative } \\
\text { abundance values (=number of transcripts/transcript length) in the } \\
\text { three libraries (germinating urediniospores, gU; appressoria, Ap; }\end{array}$} & \multicolumn{5}{|c|}{$\begin{array}{l}\text { infected leaves } 21 \text { days after inoculation, } \mathbf{H} \text { ) for transcripts according to } \\
\text { the main categories under analysis. Color scale: green to red denote } \\
\text { lowest to highest expression values for each gene. }\end{array}$} \\
\hline
\end{tabular}


superoxide dismutase, orthologs of the Cryptococcus gattii pathogenicity-required manganese superoxide dismutase gene (sod2) (Narasipura et al., 2005) were identified. Transcript 00297 is ortholog of $U$. fabae gene Uf058, P. graminis f. sp. tritici gene PGTG_04728 and M. larici-populina gene 107563. These H. vastatrix genes are up-regulated in germinating urediniospores and their proteins are predicted to be secreted, suggesting an early role in response to plant defense responses (Table 3 ).

\section{CAZymes}

The comparison of $H$. vastatrix transcripts to the carbohydrateactive enzymes (CAZymes) database (www.cazy.org; Cantarel et al., 2009) and to the predicted M. larici-populina and P. graminis f. sp. tritici CAZymes (Duplessis et al., 2011a) enabled the identification of 148 putative CAZymes in the coffee rust fungus. This number represents ca. $45 \%$ of the CAZymes in the poplar and the wheat stem rust fungi genomes (Supplementary Data 9 and Supplementary Data 4, column DB), similar to those arising from the comparison of the total number of transcripts predicted in this study to the number of genes in those two genomes. However, the number of $H$. vastatrix CAZymes transcripts varies according to the type and family of enzymes. For instance, 13 and 14 genes belonging to the Glycoside Hydrolase family 47 were identified in M. larici-populina and in P. graminis f. sp. tritici respectively, while only two transcripts were detected in $H$. vastatrix. Several other gene families are found in comparable numbers in the three fungal species, even so in the most abundant families (e.g., Carbohydrate Esterase family 4, Glycoside Hydrolase families 5 and 16, Glycosyltransferase family 2). On the contrary, some transcript families found in $H$. vastatrix are absent from the genomes of M. larici-populina (e.g., Glycosyltransferase families 25 and 43) or P. graminis f. sp. tritici (Glycoside Hydrolase families 51 and 92). Additionally, eight Glycoside Hydrolase family 7 genes were identified both in M. larici-populina and in P. graminis f. sp. tritici, but none in $H$. vastatrix transcripts. CAZyme transcripts were more frequently expressed in the gU library and less in $\mathrm{H}$ (Figure 2). Among CAZymes transcripts identified in this study, 31 presented homology to genes in the PHI database.

\section{TRANSPORTERS}

A comparison to the Transporter Classification Database (www. tcdb.org; Saier et al., 2006, 2009) and to transporters from $M$. larici-populina and P. graminis f. sp. tritici (Duplessis et al., 2011a) enabled the identification of 215 transcripts encoding putative transporters. This represents ca. $60 \%$ of the number of transporters inferred from the $M$. larici-populina and $P$. graminis $\mathrm{f}$. sp. tritici genome sequences (Duplessis et al., 2011a), again a similar proportion to that reported for other $H$. vastatrix transcript categories. However, deviations to this proportion occur in different transporter families. By instance, a family expansion is apparent in $H$. vastatrix for the F-ATPase family $(\mathrm{H}+-$ or $\mathrm{Na}$-translocating F-type, V-type and A-type ATPase) with 25 different transcripts predicted in $H$. vastatrix, against 20 in M. larici-populina, 22 in P. graminis f. sp. tritici, and 19-25 in a selection of basidiomycetes (Duplessis et al., 2011a). Similarly, variations in the $\mathrm{Ra}$ values can be related to the transporter type (Supplementary Data 10 and 11). In general, these results suggest that the transport capacity is at least as high in $\mathrm{gU}$ or Ap as in $\mathrm{H}$.

Among the $215 H$. vastatrix transcripts encoding putative transporters, 60 show homology to the PHI database. Both Ra and gene number are higher in $\mathrm{gU}$ and lower in $\mathrm{H}$ (Figure 2). Fourty are ATP-dependent transporters, including members of the ATP-binding cassette superfamily, (transcripts 01804, 07317, and 09267) and members of the P-type ATPase superfamily (transcripts 00176, 00302, 00402, 01534, and 07365), which are mostly expressed in the $\mathrm{gU}$ and Ap libraries. These results are corroborated by RT-qPCR for transcript 01534, with induction of expression both in in vitro and in planta appressorial samples (Table 3). The transcript 00302 is an ortholog of the M. oryzae P-type ATPase gene ( $p d e 1)$, required for the development of penetration hyphae and the proliferation of the fungus (Balhadère and Talbot, 2001) and was detected in the three $H$. vastatrix libraries at relatively constant expression levels. Orthologs of this gene were also identified in other rusts species (Broeker et al., 2006; Jakupović et al., 2006; Yin et al., 2009; Duplessis et al., 2011a), with elevated expression values in P. pachyrhizi appressoria (Stone et al., 2012). Among members of the Voltage-gated $\mathrm{K}^{+}$Channel $\beta$ subunit family are two transcripts (00184 and 00427) identified in the three $H$. vastatrix libraries, and one (04218) only identified in the $\mathrm{H}$ library but at higher Ra values.

\section{METABOLIC PATHWAYS}

The availability of nutrients for the fungus is very scarce at the early stages of the infection process and energy must be obtained from urediniospore contents. Carbohydrate metabolism by glycolysis/tricarboxylic acid cycle (TCA)/glyoxylate shuttle and lipids metabolism seems to be crucial to the success of the penetration process (Solomon et al., 2004). In the present study, orthologs of genes coding several key enzymes of glycolysis and TCA pathways were identified that presented higher $\mathrm{Ra}$ values in $\mathrm{gU}$ and Ap datasets (Supplementary Data 12, panels A and E). Polyols and trehalose are among the sugars mobilized during germination (D'Enfert et al., 1999; Voegele and Mendgen, 2003). One of the major roles of trehalose seems to be the regulation of glycolysis. In the trehalose biosynthetic pathway, the intermediate trehalose 6-phosphate plays an important metabolic regulatory role by controlling glycolysis through hexokinase. In $H$. vastatrix, transcript 00156, orthologous of a hexokinase, is upregulated in Ap according to RT-qPCR results. Two transcripts (04402 and 04553) were identified orthologous of trehalose-6-phosphate synthase genes in M. larici-populina (gene 33497) and P. graminis f. sp. tritici (PGT_06208), and RT-qPCR results showed the accumulation of transcript 04402 in appressoria. $H$. vastatrix transcript 00704 , an ortholog of a neutral trehalase (M. larici-populina gene 116200), was detected in the three libraries, RT-qPCR showing a peak of expression in the appressoria and at 21 days after inoculation, suggesting a close control of trehalose/trehalose-6-P levels at these stages.

The glycolysis pathway leads to the production of pyruvate after convertion into acetyl-CoA. This pathway is fundamental for cell survival since it provides intermediate metabolites and other important small molecules, such as ATP and NADH. In the present dataset, all enzymes involved in this pathway were 
detected (Supplementary Data 12, panel A). A close connection between glycolysis and other pathways such as pentose phosphates and $\beta$-oxidation suggests the existence of a tight control of carbohydrate mobilization and utilization. Dihydroxy acetone phosphate, produced by aldolase by the glycerol-3-phosphate shuttle, can lead to the formation of glycerol (Supplementary Data 12, panel C) (Cronwright et al., 2002). In H. vastatrix, transcript 08812, ortholog of a glycerol 3-phosphate dehydrogenase, was identified in the Ap library. RT-qPCR analysis (Table 3 ) further revealed its expression during pre- and post-penetration events, strongly decreasing at late colonization stages. Similarly, transcript 01400 (glycerol 3-phosphatase gene ortholog), was accumulated in gU and Ap samples (Table 3). In Saccharomyces cerevisiae, the role of glycerol has been described in the maintenance of the cytosolic redox state (Cronwright et al., 2002). Besides, in fungi such as Magnaporthe or Colletotrichum, the important turgor pressure built in appressoria is mediated by the accumulation of very large amounts of glycerol in the cell (de Jong et al., 1997; Soanes et al., 2012). In H. vastatrix, transcripts with homology to glycerol 3-phosphatase and $\mathrm{NAD}^{+}$-dependent glycerol 3-phosphate dehydrogenase (transcripts 01400 and 06448, respectively) showed higher expression during germination and appressoria formation according both to 454 pyrosequencing and RT-qPCR results. Increased levels of these enzymes were also described in P. pachyrhizi at the appressorial stage (Stone et al., 2012). The glycerol formed is metabolized by the action of a glycerol kinase (transcripts 06788 and 09049) the expression of which is also observed during appressorial formation according both to 454 pyrosequencing and RT-qPCR results, suggesting the importance of the maintenance of glycerol contents. While the sum of Ra values suggests higher expression of genes related to metabolism in the $\mathrm{H}$ library, a higher number of genes was identified in the Ap library (Figure 2).

Beyond the glycerol-3-phosphate shuttle, glycerol generation may also be achieved by the mobilization of storage lipids through degradation of triacylglycerol by triacylglycerol lipases (EC 3.1.1.3) (Thines et al., 2000). In fact, flexibility in lipid metabolism and ability to divert intermediates from glycolysis identified in $M$. oryzae was suggested to be important for rapid glycerol accumulation during appressorium development (Dean et al., 2005). In this study, the results suggested a high rate of lipid metabolism during germination and appressoria formation. Among the 16 putative lipases (transcripts 00223, 00443, 00530, 00606, 01163, 01746, 01917, 02201, 04308, 06521, 06529, 07167, 07216, 07621, and 09011), 12 were found in the gU library and nine in the Ap library, while only two transcripts were expressed in the $\mathrm{H}$ library (Supplementary Data 4). Lipid metabolism is important for ATP generation and as a source of intermediates to secondary metabolic pathways. Fatty acids are oxidized by $\beta$-oxidation, a pathway that has been referred crucial for appressorium formation, in addition to the glyoxylate cycle, to enable utilization of acetyl-CoA for central carbohydrate metabolism (Kretschmer et al., 2012; Soanes et al., 2012). The present study enabled the identification of orthologs of all genes involved in $\beta$-oxidation pathways in M. larici-populina and $P$. graminis $\mathrm{f}$. $\mathrm{sp}$. tritici (Supplementary Data 12, panel D). The comparison among the three $H$. vastatrix libraries revealed that fatty acid degradation increased in Ap as indicated by the increased expression of transcripts coding for several $\beta$-oxidation enzymes such as long-chain fatty acid CoA ligase (transcript 00175), acyl-CoA dehydrogenase (transcript 01629), enoyl CoA hydratase (transcript 01055), 3-hydroxyacyl-CoA dehydrogenase (transcript 01628), and 3ketoacyl-CoA thiolase (transcript 00191). A similar profile was detected for acyl-CoA oxidase (transcript 00622). RT-qPCR profiles for these transcripts further revealed a second peak of expression at 2 days for transcripts 00191 and 01628 , and at 7 days for transcript 00175. Transcripts 01594,01988 and 07400 are orthologs of $M$. oryzae carnitine acetyl-transferase gene (crat1), involved in transport of peroxisomal acetyl-CoA. M. oryzae deletion mutants for this gene show reduced appressoria melanisation, and are not able to elaborate penetration pegs or infection hyphae (Ramos-Pamplona and Naqvi, 2006). Interestingly, in $H$. vastatrix these transcripts were only identified in $\mathrm{gU}$ and Ap libraries, further suggesting their potential involvement in appressorium-mediated infection. RT-qPCR analyses illustrate different expression profiles for these three transcripts: while 07400 is induced during appressoria formation both in vitro and in planta, with a second peak of induction at 7 days, transcripts 01594 and 01988 are mostly over-expressed during hyphal colonization of host tissues, after 2 days for transcript 01594 and as early as appressoria differentiation for transcript 01988 (Table 3).

The glyoxylate cycle provides means for cells to assimilate twocarbon compounds into the TCA cycle and channel these via gluconeogenesis to the biosynthesis of glucose, (Supplementary Data 12, panel E). Generally, induction of the glyoxylate cycle indicates that a cell is using lipid metabolism as its predominant source for ATP generation, involving $\beta$-oxidation of fatty acids and the production of acetyl CoA. In $H$. vastatrix, results showed the presence of transcripts coding for all enzymes of the glyoxylate cycle. Ra values, as well as RT-qPCR analysis for transcripts 00491, 00717, 01133, 01266, and 08833, suggest an increasing level of expression during appressoria formation. The fact that glyoxylate cycle allows the connection between lipid and carbon metabolism may be particularly important for foliar pathogenic fungi that need to germinate and develop specific infection structures before having access to plant nutrients (Wang et al., 2003).

\section{SIGNALING}

A total of $25 \mathrm{H}$. vastatrix transcripts presented homology to genes involved in signaling, whose mutants in various fungi exhibit either loss of pathogenicity or reduced virulence phenotype (recorded in the PHI database) (Supplementary Data 5). In the cAMP pathway, transcripts 01548 and 08827 are orthologs of pathogenicity-required adenylyl cyclase $(c d c 35)$ and adenylate cyclase (cac1) genes, respectively from Candida albicans (Rocha et al., 2001) and Colletotrichum lagenarium (Yamauchi et al., 2004), necessary for filamentous growth. Matching the relevance of this gene for spore germination and differentiation of infection structures from appressoria, RT-qPCR analysis showed the accumulation of transcript 08827 at the appressorial stage and of transcript 01548 at early infection stages, from urediniospore germination until 3 days (Table 3). Also, transcripts 00898 and 01431 are orthologs of the Colletotrichum trifolii pathogenicity-required catalytic subunit of cyclic AMP-dependent protein kinase gene 
(pkac), necessary for penetration and sporulation (Yang and Dickman, 1999). RT-qPCR profiles showed induction of their expression in appressorial samples both obtained in vitro and in planta (Table 3), compatible with the involvement of these genes in penetration. Another protein kinase involved in the cAMP pathway is the $M$. oryzae/C. trifolii pathogenicity-required cpkA gene, ortholog of $H$. vastatrix transcript 06436 , required for appressorium formation and pathogenesis (Mitchell and Dean, 1995; Yang and Dickman, 1999). RT-qPCR results further suggested an activation of the expression of this transcript in the appressorial stage (Table 3 ).

Several MAP kinases and serine/threonine kinases were identified, and RT-qPCR results further corroborated induction of their expression in germinating urediniospores and/or in appressoria. By instance, orthologs of the Ustilago maydis kpp6 and $u b c 3$ genes (Mayorga and Gold, 1999; Brachmann et al., 2003), the Cryphonectria parasitica cpmk1 gene (Park et al., 2004), the Claviceps purpurea cpmk1 gene (Mey et al., 2002) and the Cryptococcus neoformans var. grubii hog1 gene (Bahn et al., 2005) were identified. H. vastatrix transcripts 06883 and 07140 , orthologs respectively of the C. purpurea and of C. parasitica $c p m k 1$ genes, were both identified only in the gU library. RTqPCR analysis showed distinct expression profiles, with transcript 06883 induced at pre-penetration stages only, and transcript 07140 expressed at all infection stages except late colonization and resting urediniospores (Table 3 ). On the contrary, both the $u b c 3$ type transcript 00373 and the hog1 type transcript 00616 were identified in the three libraries showing stable expression profiles, as corroborated by RT-qPCR results (Table 3). In $M$. oryzae, the Pmk1 MAP-kinase pathway has a major role in controlling appressorium morphogenesis (Soanes et al., 2012). Also, two MAPK kinases (MAP2K) were identified, corresponding to transcripts 01932 and 01813 , of the Ste7 and the Mkk1 types respectively (Hamel et al., 2012), both of them identified in the $\mathrm{gU}$ and Ap libraries. RT-qPCR results further showed that the expression of transcript 01932 is observed at early infection stages (Table 3). The $H$. vastatrix transcripts 00125 and 00489 , and 00409, orthologs respectively of the of the M. oryzae MAP kinaseregulated gas 1 and gas2 genes (Xue et al., 2002), were identified in the three libraries, with high expression levels $(\mathrm{Ra}>1)$ in the $\mathrm{gU}$ and Ap libraries. RT-qPCR results corroborate the induction of expression of these transcripts in germinating urediniospores and in appressoria, with a second peak of expression recorded for transcripts 00409 and 00489 respectively at 2 and 3 days (Table 3 ). Interestingly, transcript accumulation for gas orthologs in $P$. pachyrhizi and Uromyces appendiculatus purified haustoria were also reported (Link et al., 2013). The present results indicated that gas expression is not solely related to the rust haustorial infection structure, but also to earlier stages such as spore germination. A group of $H$. vastatrix transcripts show homology to G protein subunits genes from the PHI base. Heterotrimeric G-proteins transduce extracellular signals to various downstream effectors (e.g., MAP kinases) in eukaryotic cells. Transcript 06565 shows homology to the Cryptococcus neoformans virulence-related gpa1 gene (Alspaugh et al., 1997) and to the M. larici-populina heterotrimeric G-protein $\alpha$ subunit 3 gene (gpa3) (Duplessis et al., 2011a). In $H$. vastatrix, transcript 06565 was only detected in the
gU library, suggesting an involvement in pre-penetration events, in agreement with the profile of its M. larici-populina ortholog (gene 47478) (Duplessis et al., 2012). Orthologs of G-protein $\beta$ subunit genes involved in appressorium formation, including genes $m g b 1$ from M. oryzae (Nishimura et al., 2003), cgb1 from Cochliobolus heterostrophus (Ganem et al., 2004) and Bpp1 from $U$. maydis (Müller et al., 2004), were identified in $H$. vastatrix (transcripts 00968 and 02022 for $m g b 1$ and 07174 for $c g b 1 / B p p 1$ ), all of them in the $\mathrm{gU}$ library, indicative of a possible role in appressoria formation in $H$. vastatrix. RT-qPCR expression profiling further showed induction of transcripts 02022 and 07174 during early pre-penetration events (Table 3 ).

\section{OTHER GENES IDENTIFIED IN RUST TRANSCRIPTOMIC/GENOMIC STUDIES}

Several orthologs of $U$. fabae in planta-induced genes (PIGs) were identified in $H$. vastatrix (Supplementary Data 13 ). The $U$. fabae PIGs genes showed induced expression in Vicia faba infected leaves as compared to germinating urediniospores (Jakupović et al., 2006). The majority of $U$. fabae transcripts with a predicted function have orthologs in H. vastatrix (Supplementary Data 13).

A comparison of $H$. vastatrix genes to $P$. pachyrhizi genes expressed in germinating urediniospores (Posada-Buitrago and Frederick, 2005) reveals that the two most expressed $P$. pachyrhizi genes, $P p 0104$ and $P p 0417$, have no significant homologies in $H$. vastatrix (Supplementary Data 14). In the same way, the comparison of the $9234 \mathrm{H}$. vastatrix transcript to a collection of ESTs and proteins differentially expressed in $P$. pachyrhizi appressoria (Stone et al., 2012) shows a very limited number of genes in common between both studies (Supplementary Data 14). Interestingly however, the comparison of 4492 P. pachyrhizi haustorial ESTs (Link et al., 2013) to the 9234 H. vastatrix transcripts identified 1668 hits to 1132 unique $H$. vastatrix transcripts. Half of them corresponded to $H$. vastatrix transcripts not detected in the H library (Supplementary Data 14). A similar situation was observed when comparing the 7561 U. appendiculatus haustorial ESTs (Link et al., 2013) to the H. vastatrix transcripts (data not shown).

Among the $156 \mathrm{M}$. larici-populina annotated genes that are $>10$-fold up-regulated in infected leaves as compared to urediniospores (Duplessis et al., 2011a), only 22\% have orthologs in the present $H$. vastatrix dataset, including 12 transporters (mostly sugar and ion transporters), 10 secreted proteins and six glycoside hydrolases (Supplementary Data 4, columns Y-AA). Among the 235 P. graminis f. sp. tritici annotated genes that are the $>10$-fold up-regulated in infected leaves as compared to urediniospores (Duplessis et al., 2011a), 49\% have orthologs in the present $H$. vastatrix dataset, although half of these are predicted ribosomal genes. Unlike for M. larici-populina, none of these P. graminis $\mathrm{f}$. sp. tritici genes include glycoside hydrolases or secreted proteins and only two transporters were identified.

An expanded number of multigene families have been reported in M. larici-populina and $P$. graminis f. sp. tritici as compared to other Basidiomycetes (Duplessis et al., 2011a). Among those expanded families, the number of $H$. vastatrix transcriptsbased predicted genes is higher than those for M. larici-populina or $P$. graminis f. sp. tritici for the major facilitator superfamily, 
helicase or chitinase, and under-represented for families such as serine/threonine protein kinase and sugar transporter (Table 6). While the current study does not cover all differentiation stages of the $H$. vastatrix life cycle and transcripts expressed at low level may not be represented, it is interesting to note that some gene families are over-represented in comparison to annotated genome sequences.

\section{CONCLUSIONS}

In this study, 7894 contigs were obtained by 454 pyrosequencing of cDNA from $H$. vastatrix germinating urediniospores and appressoria. These transcripts, along with 4465 in planta expressed contigs (Fernandez et al., 2012), were assembled into 9234 annotated transcripts. This number represents an important fraction $(>50 \%)$ of the genes predicted in rust sequenced genomes so far (Duplessis et al., 2012). In addition, this elevated gene number for $H$. vastatrix is corroborated by other database comparisons, such as the core fungal genes database (FUNYBASE), the carbohydrate-active enzymes (CAZy) database or the Transporter Classification Database (TCDB). Database comparisons further indicate that half of these transcripts (4707) present no significant homology to genomic or transcriptomic data from other rusts, potentially representing novel or very divergent $H$. vastatrix genes.

Annotation of $H$. vastatrix transcripts and comparison of their relative abundance in each of the three sampling stages suggest a particularly active metabolism, translational activity, production of new structures and signaling in appressoria and intense transport, secretory activity and cellular multiplication in germinating urediniospores (Figure 2). Transcripts encoding putative carbohydrate-active enzymes and different types of transporters are more expressed in germinating urediniospores and appressoria, and lesser at late infection stages. Among transcripts involved in metabolic pathways,

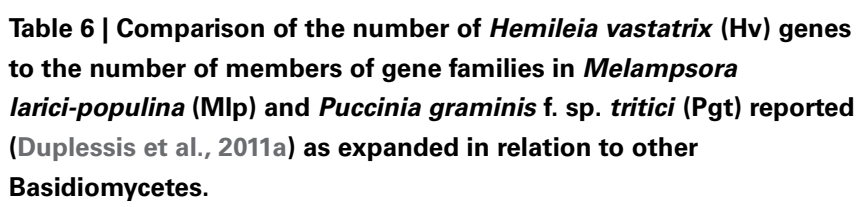

\begin{tabular}{llll}
\hline Gene family & Hv & MIp & Pgt \\
\hline Amino acid transporter & 12 & 11 & 12 \\
Carbohydrate deacetylase & 11 & 11 & 10 \\
Cell division/GTP binding protein & 13 & 6 & 13 \\
Chitinase & 33 & 14 & 9 \\
Helicase & 19 & 14 & 13 \\
Histone H3 & 9 & 11 & 8 \\
Major facilitator superfamily & 50 & 29 & 17 \\
Serine/threonine protein kinase & 36 & 87 & 73 \\
Sugar transporter & 7 & 19 & 15 \\
Superoxide dismutase & 6 & 7 & 20 \\
Zinc finger protein & 29 & 4 & 67 \\
\hline
\end{tabular}

Colour scale: green to red denote lowest to highest number of genes for each gene family. an active lipid metabolism was observed at pre-penetration stages compared to late infection stages, while aminoacid and carbohydrate metabolism was more active in post-penetration samples. Moreover, the homology of $H$. vastatrix transcripts to genes known to be involved and/or required for pathogenicity in other fungal plant pathogens, namely in appressoriamediated infection, enabled the identification of an array of putative pathogenicity factors, a large proportion of which are expressed as early as during germ-tube elongation. Also, while melanized cuticle-breaching appressoria have been thoroughly investigated over the last few decades, namely in $M$. oryzae and Colletotrichum spp. (Deising et al., 2000; Kleemann et al., 2012), the present study represents an important insight into genes expressed in non-melanized stomata-penetrating appressoria. To this end, induction of expression of genes related to the production of carbohydrate-active enzymes and to the accumulation of glycerol in germinating urediniospores and appressoria suggests that combined lytic and physical mechanisms are involved in appressoria-mediated penetration of coffee leaf stomata.

This early activation of signaling, transport and secretory pathways suggests a precocious plant-fungus dialogue, which is corroborated by the possible induction of an hypersensitive reaction in stomatal cells of some resistant coffee varieties as early as at the appressorial stage (Silva et al., 2002; Ganesh et al., 2006; Diniz et al., 2012), thus prompting further studies targeting the identification of virulence/avirulence factors (and their resistance/susceptibility conterparts) expressed at these early stages of the plant-fungus interaction.

\section{AUTHOR CONTRIBUTIONS}

This study was conceived and directed by Pedro Talhinhas, Helena G. Azinheira, Sébastien Duplessis, Maria do Céu Silva, and Diana Fernandez. The laboratorial experiments were conducted by Pedro Talhinhas, Helena G. Azinheira, Andreia Loureiro, Sílvia Tavares, and Anne-Sophie Petitot. 454-pyrosequencing was conducted by Julie Poulain and Corinne Da Silva. Bioinformatic analyses were conducted by Bruno Vieira, Emmanuelle Morin, and Octávio S. Paulo. Biological interpretation of bioinformatics analyses were conducted by Pedro Talhinhas, Helena G. Azinheira, Andreia Loureiro, Sílvia Tavares, Sébastien Duplessis, and Diana Fernandez. Pedro Talhinhas, Helena G. Azinheira, Andreia Loureiro, Sílvia Tavares, Dora Batista, Octávio S. Paulo, Sébastien Duplessis, Maria do Céu Silva, and Diana Fernandez wrote the paper. All authors read and approved the final manuscript.

\section{ACKNOWLEDGMENTS}

This work was undertaken through a French-Portuguese collaborative project (Partenariat Hubert Curien PHC-Pessoa 22583XM) funded by the Ministère des Affaires Étrangères et Européennes of France. The work was funded by Portuguese national funds through Fundação para a Ciência e a Tecnologia (projects PTDC/AGR-AAM/71866/2006 and PTDC/AGRGPL/114949/2009 and grants SFRH/BPD/47008/2008, SFRH/BPD/65965/2009 and SFRH/BPD/88994/2012), and by CEA/Genoscope-INRA-IRD Collaborative project (http:// 
www.genoscope.cns.fr/spip/Identification-of-virulence.html) (France), whose funding is gratefully acknowledged.

\section{SUPPLEMENTARY MATERIAL}

The Supplementary Material for this article can be found online at: http://www.frontiersin.org/journal/10.3389/fpls.2014. 00088/abstract

\section{REFERENCES}

Aime, M. C. (2006). Toward resolving family-level relationships in rust fungi (Uredinales). Mycoscience 47, 112-122. doi: 10.1007/s10267-006-0281-0

Alspaugh, J. A., Perfect, J. R., and Heitman, J. (1997). Cryptococcus neoformans mating and virulence are regulated by the G-protein alpha subunit GPA1 and cAMP. Genes Dev. 11, 3206-3217. doi: 10.1101/gad.11.23.3206

Altschul, S. F., Madden, T. L., Schäffer, A. A., Zhang, J., Zhang, Z., Miller, W., et al. (1997). Gapped BLAST and PSI-BLAST: a new generation of protein database search programs. Nucleic Acids Res. 25, 3389-3402. doi: 10.1093/nar/25. 17.3389

Azinheira, H. G., Silva, M. C., Guerra-Guimarães, L., Mendgen, K., Rodrigues, Jr., and C., Pinto Ricardo, C. (2001). "Development of infection structures of Hemileia vastatrix on artificial membranes," in 11th Conference of the Mediterranean Phytopathological Union, 17-20 September 2001 (Évora: Andalus Academic Publishing), 353-355.

Bahn, Y. S., Kojima, K., Cox, G. M., and Heitman, J. (2005). Specialization of the HOG pathway and its impact on differentiation and virulence of Cryptococcus neoformans. Mol. Biol. Cell 16, 2285-2300. doi: 10.1091/mbc.E04-11-0987

Balhadère, P. V., and Talbot, N. J. (2001). PDE1 encodes a P-type ATPase involved in appressorium-mediated plant infection by the rice blast fungus Magnaporthe grisea. Plant Cell 13, 1987-2004. doi: 10.1105/TPC.010056

Barrett, L. G., Thrall, P. H., Dodds, P. N., van der Merwe, M., Linde, C. C., Lawrence, G. J., et al. (2009). Diversity and evolution of effector loci in natural populations of the plant pathogen Melampsora lini. Mol. Biol. Evol. 26, 2499-2513. doi: 10.1093/molbev/mspl66

Brachmann, A., Schirawski, J., Müller, P., and Kahmann, R. (2003). An unusual MAP kinase is required for efficient penetration of the plant surface by Ustilago maydis. EMBO J. 22, 2199-2210. doi: 10.1093/emboj/cdg198

Broeker, K., Bernard, F., and Moerschbacher, B. M. (2006). An EST library from Puccinia graminis f. sp. tritici reveals genes potentially involved in fungal differentiation. FEMS Microbiol. Lett. 256, 273-281. doi: 10.1111/j.15746968.2006.00127.x

Cantarel, B. L., Coutinho, P. M., Rancurel, C., Bernard, T., Lombrad, V., and Henrissat, B. (2009). The Carbohydrate-Active EnZymes database (CAZy): an expert resource for glycogenomics. Nucleic Acids Res. 37, D233-D238. doi: 10.1093/nar/gkn663

Cantu, D., Govindarajulu, M., Kozik, A., Wang, M., Chen, X., Kojima, K. K., et al. (2011). Next generation sequencing provides rapid access to the genome of Puccinia striiformis f. sp. tritici, the causal agent of wheat stripe rust. PLoS ONE 6:e24230. doi: 10.1371/journal.pone.0024230

Catanzariti, A.-M., Dodds, P. N., Lawrence, G. J., Ayliffe, M. A., and Ellis, J. G. (2006). Haustorially-expressed secreted proteins from flax rust are highly enriched for avirulence elicitors. Plant Cell 18, 243-256. doi: 10.1105/tpc.105.035980

Chen, Z. J., Nunes, M. A., Silva, M. C., and Rodrigues, C. J. (2004). Appressorium turgor pressure of Colletotrichum kahawae might have a role in coffee cuticle penetration. Mycologia 96, 1199-1208. doi: 10.2307/3762135

Cressey, D. (2013). Coffee rust regains foothold. Nature 493, 587. doi: 10.1038/493587a

Cronwright, G. R., Rohwer, J. R., and Prior, B. A. (2002). Metabolic control analysis of glycerol synthesis in Saccharomyces cerevisiae. Appl. Environ. Microbiol. 68, 4448-4456. doi: 10.1128/AEM.68.9.4448-4456.2002

D'Enfert, C., Bonini, B. M., Zapella, P. D. A., Fontaine, T., da Silva, A. M., and Terenzi, H. F. (1999). Neutral trehalases catalyse intracellular trehalose breakdown in the filamentous fungi Aspergillus nidulans and Neurospora crassa. Mol. Microbiol. 32, 471-484. doi: 10.1046/j.1365-2958.1999.01327.x

Dean, R. A., Talbot, N. J., Ebbole, D. J., Farman, M. L., Mitchell, T. K., Orbach, M. J., et al. (2005). The genome sequence of the rice blast fungus Magnaporthe grisea. Nature 434, 980-986. doi: 10.1038/nature03449
Deising, H. B., Werner, S., and Wernitz, M. (2000). The role of fungal appressoria in plant infection. Microbes Infect. 2, 1631-1641. doi: 10.1016/S12864579(00)01319-8

de Jong, J. C., McCormack, B. J., Smirnoff, N., and Talbot, N. J. (1997). Glycerol generates turgor in rice blast. Nature 389, 244-245. doi: 10.1038/38418

Diniz, I., Talhinhas, P., Azinheira, H. G., Várzea, V., Medeira, C., Maia, I., et al. (2012). Cellular and molecular analyses of coffee resistance to Hemileia vastatrix and nonhost resistance to Uromyces vignae in the resistance-donor genotype HDT832/2. Eur. J. Plant Pathol. 133, 141-157. doi: 10.1007/s10658-0119925-9

Dodds, P. N., Lawrence, G. J., Catanzariti, A.-M., Ayliffe, M. A., and Ellis, J. G. (2004). The Melampsora lini AvrL567 avirulence genes are expressed in haustoria and their products are recognized inside plant cells. Plant Cell 16, 755-768. doi: $10.1105 /$ tpc.020040

Dodds, P. N., Lawrence, G. J., Catanzariti, A.-M., Teh, T., Wang, C. I. A., Ayliffe, M. A., et al. (2006). Direct protein interaction underlies gene-for-gene specificity and coevolution of the flax resistance genes and flax rust avirulence genes. Proc. Natl. Acad. Sci. U.S.A. 103, 8888-8893. doi: 10.1073/pnas.0602577103

Duplessis, S., Cuomo, C. A., Lin, Y.-C., Aerts, A., Tisserant, E., Veneault-Fourrey, C., et al. (2011a). Obligate biotrophy features unraveled by the genomic analysis of rust fungi. Proc. Natl. Acad. Sci. U.S.A. 108, 9166-9171. doi: $10.1073 /$ pnas. 1019315108

Duplessis, S., Hacquard, S., Delaruelle, C., Tisserant, E., Frey, P., Martin, F., et al. (2011b) Melampsora larici-populina transcript profiling during germination and time-course infection of poplar leaves reveals dynamic expression patterns associated with virulence and biotrophy. Mol. Plant-Microbe Interact. 24, 808-818. doi: 10.1094/MPMI-01-11-0006

Duplessis, S., Joly, D. L., and Dodds, P. N. (2012). "Rust effectors," in Effectors in Plant-Microbe Interactions, eds F. Martin and S. Kamoun (New York, NY: Wiley), 155-193.

Ekblom, R., Balakrishnan, C. N., Burke, T., and Slate, J. (2010). Digital gene expression analysis of the zebra finch genome. BMC Genomics 11:219. doi: 10.1186/1471-2164-11-219

Emanuelsson, O., Nielsen, H., Brunak, S., and von Heijne, G. (2000). Predicting subcellular localization of proteins based on their N-terminal amino acid sequence. J. Mol. Biol. 300, 1005-1016. doi: 10.1006/jmbi.2000.3903

Fernandez, D., Talhinhas, P., and Duplessis, S. (2013). "Rust fungi: achievements and future challenges on genomics and host-parasite interactions," in The Mycota XI, Agricultural Applications 2nd Edn., ed F. Kempken (Berlin: Springer-Verlag), 315-341.

Fernandez, D., Tisserant, E., Talhinhas, P., Azinheira, H. G., Vieira, A., Loureiro, A., et al. (2012). 454-pyrosequencing of Coffea arabica leaves infected by the rust fungus Hemileia vastatrix reveals in planta expressed pathogen secreted proteins and plant functions expressed in a late compatible plant-rust interaction. Mol. Plant Pathol. 13, 17-37. doi: 10.1111/j.1364-3703.2011.00723.x

Ganem, S., Lu, S. W., Lee, B. N., Chou, D. Y., Hadar, R., Turgeon, B. G., et al. (2004). G-protein beta subunit of Cochliobolus heterostrophus involved in virulence, asexual and sexual reproductive ability, and morphogenesis. Eukaryot. Cell 3, 1653-1663. doi: 10.1128/EC.3.6.1653-1663.2004

Ganesh, D., Petitot, A., Silva, M. C., Alary, R., Lecouls, A. C., and Fernandez, D. (2006). Monitoring of the early molecular resistance responses of coffee (Coffea arabica L.) to the rust fungus (Hemileia vastatrix) using real-time quantitative RT-PCR. Plant Sci. 170, 1045-1051. doi: 10.1016/j.plantsci.2005.12.009

Hacquard, S., Joly, D. L., Lin, Y.-C., Tisserant, E., Feau, N., Delaruelle, C., et al. (2012). A comprehensive analysis of genes encoding small secreted proteins identifies candidate effectors in Melampsora larici-populina (poplar leaf rust). Mol. Plant Microbe Interact. 25, 279-293. doi: 10.1094/MPMI-09-11-0238

Hall, T. A. (1999). BioEdit: a user-friendly biological sequence alignment editor and analysis program for Windows 95/98/NT. Nucl. Acids Symp. Ser. 41, 95-98.

Hamel, L.-P., Nicole, M.-C., Duplessis, S., and Ellis, B. E. (2012). Mitogen-activated protein kinase signaling in plant-interacting fungi: distinct messages from conserved messengers. Plant Cell 24, 1327-1351. doi: 10.1105/tpc.112.096156

Howard, R. J., Ferrari, M. A., Roach, D. H., and Money, N. P. (1991). Penetration of hard substrates by a fungus employing enormous turgor pressures. Proc. Natl. Acad. Sci. U.S.A. 88, 11281-11284. doi: 10.1073/pnas.88.24.11281

Hu, G. G., Linning, R., McCallum, B., Banks, T., Cloutier, S., Butterfield, Y., et al. (2007). Generation of a wheat leaf rust, Puccinia triticina, EST database from stage-specific cDNA libraries. Mol. Plant Pathol. 8, 451-467. doi: 10.1111/j.1364-3703.2007.00406.x 
Jakupović, M., Heintz, M., Reichmann, P., Mendgen, K., and Hahn, M. (2006). Microarray analysis of expressed sequence tags from haustoria of the rust fungus Uromyces fabae. Fungal Genet. Biol. 43, 8-19. doi: 10.1016/j.fgb.2005.09.001

Kemen, E., Kemen, A. C., Rafiqi, M., Hempel, U., Mendgen, K., Hahn, M., et al. (2005). Identification of a protein from rust fungi transferred from haustoria into infected plant cells. Mol. Plant Microbe Interact. 18, 1130-1139. doi: 10.1094/MPMI-18-1130

Kleemann, J., Rincon-Rivera, L. J., Takahara, H., Neumann, U., Ver Loren van Themaat, E., van der Does, H. C., et al. (2012). Sequential delivery of hostinduced virulence effectors by appressoria and intracellular hyphae of the phytopathogen Colletotrichum higginsianum. PLoS Pathog. 8:e1002643. doi: 10.1371/journal.ppat.1002643

Kretschmer, M., Klose, J., and Kronstad, J. W. (2012). Defects in mitochondrial and peroxisomal $\beta$-oxidation influence virulence in the maize pathogen Ustilago maydis. Eukaryot. Cell 11, 1055-1066. doi: 10.1128/EC.00129-12

Krogh, A., Larsson, B., von Heijne, G., and Sonnhammer, E. L. (2001). Predicting transmembrane protein topology with a hidden Markov model: application to complete genomes. J. Mol. Biol. 305, 567-580. doi: 10.1006/jmbi.2000.4315

Kumar, S., and Blaxter, M. L. (2010). Comparing de novo assemblers for 454 transcriptome data. BMC Genomics 11:571. doi: 10.1186/1471-2164-11-571

Link, T. I., Lang, P., Scheffler, B. E., Duke, M. V., Graham, M. A., Cooper, B., et al. (2013). The haustorial transcriptomes of Uromyces appendiculatus and Phakopsora pachyrhizi and their candidate effector families. Mol. Plant Pathol. doi: 10.1111/mpp.12099. [Epub ahead of print].

Mank, J. E., Hultin-Rosenberg, L., Zwahlen, M., and Ellegren, H. (2008). Pleiotropic constraint hampers the resolution of sexual antagonism in vertebrate gene expression. Am. Nat. 171, 35-43. doi: 10.1086/523954

Marthey, S., Aguileta, G., Rodolphe, F., Gendrault, A., Giraud, T., Fournier, E., et al. (2008). FUNYBASE: a FUNgal phYlogenomic dataBASE. BMC Bioinformatics 9:456. doi: 10.1186/1471-2105-9-456

Mayorga, M. E., and Gold, S. E. (1999). A MAP kinase encoded by the ubc3 gene of Ustilago maydis is required for filamentous growth and full virulence. Mol. Microbiol. 34, 485-497. doi: 10.1046/j.1365-2958.1999.01610.x

Mey, G., Oeser, B., Lebrun, M. H., and Tudzynski, P. (2002). The biotrophic, non-appressorium-forming grass pathogen Claviceps purpurea needs a Fus3/Pmk1 homologous mitogen-activated protein kinase for colonization of rye ovarian tissue. Mol. Plant Microbe Interact. 15, 303-312. doi: 10.1094/MPMI.2002.15.4.303

Mitchell, T. K., and Dean, R. A. (1995). The cAMP-dependent protein kinase catalytic subunit is required for appressorium formation and pathogenesis by the rice blast pathogen Magnaporthe grisea. Plant Cell 7, 1869-1878.

Müller, P., Leibbrandt, A., Teunissen, H., Cubasch, S., Aichinger, C., and Kahmann, R. (2004). The G $\beta$-subunit-encoding gene bpp 1 controls cyclic-AMP signaling in Ustilago maydis. Eukaryot. Cell 3, 806-814. doi: 10.1128/EC.3.3.806-814.2004

Narasipura, S. D., Chaturvedi, V., and Chaturvedi, S. (2005). Characterization of Cryptococcus neoformans variety gattii SOD2 reveals distinct roles of the two superoxide dismutases in fungal biology and virulence. Mol. Microbiol. 55, 1782-1800. doi: 10.1111/j.1365-2958.2005.04503.x

Nishimura, M., Park, G., and Xu, J. R. (2003). The G-beta subunit MGB1 is involved in regulating multiple steps of infection-related morphogenesis in Magnaporthe grisea. Mol. Microbiol. 50, 231-243. doi: 10.1046/j.1365-2958.2003.03676.x

Park, S. M., Choi, E. S., Kim, M. J., Cha, B. J., Yang, M. S., and Kim, D. H. (2004). Characterization of HOG1 homologue, CpMK1, from Cryphonectria parasitica and evidence for hypovirus-mediated perturbation of its phosphorylation in response to hypertonic stress. Mol. Microbiol. 51, 1267-1277. doi: 10.1111/j.1365-2958.2004.03919.x

Petersen, T. N., Brunak, S., von Heijne, G., and Nielsen, H. (2011). SignalP 4.0: discriminating signal peptides from transmembrane regions. Nat. Methods 8 , 785-786. doi: 10.1038/nmeth.1701

Posada-Buitrago, M. L., and Frederick, R. D. (2005). Expressed sequence tag analysis of the soybean rust pathogen Phakopsora pachyrhizi. Fungal Genet. Biol. 42, 949-962. doi: 10.1016/j.fgb.2005.06.004

Pretsch, K., Kemen, A., Kemen, E., Geiger, M., Mendgen, K., and Voegele, R. (2013). The rust transferred proteins - a new family of effector proteins exhibiting protease inhibitor function. Mol. Plant Pathol. 14, 96-107. doi: 10.1111/j.13643703.2012.00832.x

Ramos-Pamplona, M., and Naqvi, N. I. (2006). Host invasion during rice-blast disease requires carnitine-dependent transport of peroxisomal acetyl-CoA. Mol. Microbiol. 61, 61-75. doi: 10.1111/j.1365-2958.2006.05194.x
Rocha, C. R., Schröppel, K., Harcus, D., Marcil, A., Dignard, D., Taylor, B. N., et al. (2001). Signaling through adenylyl cyclase is essential for hyphal growth and virulence in the pathogenic fungus Candida albicans. Mol. Biol. Cell 12, 3631-3643. doi: $10.1091 / \mathrm{mbc} .12 .11 .3631$

Saier, M. H. Jr., Tran, C. V., and Barabote, R. D. (2006). TCDB: the transporter classification database for membrane transport protein analyses and information. Nucleic Acids Res. 34, D181-D186. doi: 10.1093/nar/gkj001

Saier, M. H. Jr., Yen, M. R., Noto, K., Tamang, D. G., and Elkan, C. (2009). The Transporter Classification Database: recent advances. Nucleic Acids Res. 37, D274-D278. doi: 10.1093/nar/gkn862

Silva, D. N., Vieira, A., Talhinhas, P., Azinheira, H. G., Silva, M. C., Fernandez, D., et al. (2012). "Phylogenetic analysis of Hemileia vastatrix and related taxa using a genome-scale approach," in Proceedings of the 24th International Conference on Coffee Science, 11-16 November 2012, San José, ed Association for Science and Information on Coffee (Paris), 1404-1408.

Silva, M. C., Nicole, M., Guerra-Guimarães, L., and Rodrigues, C. J. Jr. (2002). Hypersensitive cell death and post-haustorial defence responses arrest the orange rust (Hemileia vastatrix) growth in resistant coffee leaves. Physiol. Mol. Plant Pathol. 60, 169-183. doi: 10.1006/pmpp.2002.0389

Silva, M. C., Várzea, V., Guimarães, L. G., Azinheira, H. G., Fernandez, D., Petitot, A., et al. (2006). Coffee resistance to the main diseases: leaf rust and coffee berry disease. Braz. J. Plant Physiol. 18, 119-147. doi: 10.1590/S167704202006000100010

Soanes, D. M., Chakrabarti, A., Paszkiewicz, K. H., Dawe, A. L., and Talbot, N. J. (2012). Genome-wide transcriptional profiling of appressorium development by the rice blast fungus Magnaporthe oryzae. PLoS Pathog. 8:e1002514. doi: 10.1371/journal.ppat.1002514

Soanes, D. M., and Talbot, N. J. (2006). Comparative genomic analysis of phytopathogenic fungi using expressed sequence tag (EST) collections. Mol. Plant Pathol. 7, 61-70. doi: 10.1111/j.1364-3703.2005.00317.x

Solomon, P. S., Lee, R. C., Wilson, T. J. G., and Oliver, R. P. (2004). Pathogenicity of Stagonospora nodorum requires malate synthase. Mol. Microbiol. 53, 1065-1073. doi: 10.1111/j.1365-2958.2004.04178.x

Stone, C. L., McMahon, M. B., Fortis, L. L., Nuñez, A., Smythers, G. W., Luster, D. G., et al. (2012). Gene expression and proteomic analysis of the formation of Phakopsora pachyrhizi appressoria. BMC Genomics 13:269. doi: 10.1186/14712164-13-269

Tatusov, R. L. (2003). The COG database: an updated version includes eukaryotes. BMC Bioinformatics 4:41. doi: 10.1186/1471-2105-4-41

Terhune, B. T., Bojko, R. J., and Hoch, H. C. (1993). Deformation of stomatal guard cell lips and microfabricated artificial topographies during appressorium formation. Exp. Mycol. 17, 70-78. doi: 10.1006/emyc. 1993.1006

Thines, E., Weber, R. W., and Talbot, N. J. (2000). MAP kinase and protein kinase A-dependent mobilization of triacylglycerol and glycogen during appressorium turgor generation by Magnaporthe grisea. Plant Cell 12, 1703-1718. doi: 10.1105/tpc.12.9.1703

Várzea, V. M. P., and Marques, D. V. (2005). "Population variability of Hemileia vastatrix vs coffee durable resistance," in Durable Resistance to Coffee Leaf Rust, eds L. Zambolim, E. Zambolim, and V. M. P. Várzea (Viçosa: Universidade Federal de Viçosa), 53-74.

Vega-Arreguín, J. C., Ibarra-Laclette, E., Jiménez-Moraila, B., Martínez, O., VielleCalzada, J. P., Herrera-Estrella, L., et al. (2009). Deep sampling of the Palomero maize transcriptome by a high throughput strategy of pyrosequencing. BMC Genomics 10:299. doi: 10.1186/1471-2164-10-299

Vieira, A., Talhinhas, P., Loureiro, A., Duplessis, S., Fernandez, D., Silva, M. C., et al. (2011). Validation of RT-qPCR reference genes for in planta expression studies in Hemileia vastatrix, the causal agent of coffee leaf rust. Fungal Biol. 115, 891-901. doi: 10.1016/j.funbio.2011.07.002

Vieira, A., Talhinhas, P., Loureiro, A., Thürich, J., Duplessis, S., Fernandez, D., et al. (2012). Expression profiling of genes involved in the biotrophic colonisation of Coffea arabica leaves by Hemileia vastatrix. Eur. J. Plant Pathol. 133, 261-277. doi: 10.1007/s10658-011-9864-5

Voegele, R. T., Hahn, M., and Mendgen, K. (2009). "The uredinales: cytology, biochemistry, and molecular biology," in The Mycota, 5. Plant Relationships. Vol. 2, ed H. Deising (Berlin: Springer), 69-98.

Voegele, R. T., and Mendgen, K. (2003). Rust haustoria: nutrient uptake and beyond. New Phytol. 159, 93-100. doi: 10.1046/j.1469-8137.2003.00761.x 
Wang, Z. Y., Thornton, C. R., Kershaw, M. J., Debao, L., and Talbot, N. J. (2003). The glyoxylate cycle is required for temporal regulation of virulence by the plant pathogenic fungus Magnaporthe grisea. Mol. Microbiol. 47, 1601-1612. doi: 10.1046/j.1365-2958.2003.03412.x

Winnenburg, R., Baldwin, T. K., Urban, M., Rawlings, C., Köhler, J., and Hammond-Kosack, K. E. (2007). PHI-base: a new database for pathogen host interactions. Nucleic Acids Res. 34, D459-D464. doi: 10.1093/nar/gkm858

Xue, C., Park, G., Choi, W., Zheng, L., Dean, R. A., and Xu, J. R. (2002). Two novel fungal virulence genes specifically expressed in appressoria of the rice blast fungus. Plant Cell 14, 2107-2119. doi: 10.1105/tpc.003426

Yamauchi, J., Takayanagi, N., Komeda, K., Takano, Y., and Okuno, T. (2004). cAMPpKA signaling regulates multiple steps of fungal infection cooperatively with Cmk1 MAP kinase in Colletotrichum lagenarium. Mol. Plant Microbe Interact. 17, 1355-1365. doi: 10.1094/MPMI.2004.17.12.1355

Yanai, I., Benjamin, H., Shmoish, M., Chalifa-Caspi, V., Shklar, M., Ophir, R., et al. (2005). Genome-wide midrange transcription profiles reveal expression level relationships in human tissue specification. Bioinformatics 21, 650-659. doi: 10.1093/bioinformatics/bti042

Yang, Z., and Dickman, M. B. (1999). Colletotrichum trifolii mutants disrupted in the catalytic subunit of cAMP-dependent protein kinase are nonpathogenic. Mol. Plant Microbe Interact. 12, 430-439. doi: 10.1094/MPMI.1999.12.5.430

Yin, C., Chen, X., Wang, X., Han, Q., Kang, Z., and Hulbert, S. H. (2009). Generation and analysis of expression sequence tags from haustoriaof the wheat stripe rust fungus Puccinia striiformis f. sp. tritici. BMC Genomics 10:626. doi: 10.1186/1471-2164-10-626

Conflict of Interest Statement: The authors declare that the research was conducted in the absence of any commercial or financial relationships that could be construed as a potential conflict of interest.

Received: 22 January 2014; paper pending published: 06 February 2014; accepted: 24 February 2014; published online: 14 March 2014.

Citation: Talhinhas P, Azinheira HG, Vieira B, Loureiro A, Tavares S, Batista D, Morin E, Petitot A-S, Paulo OS, Poulain J, Da Silva C, Duplessis S, Silva MC and Fernandez $D$ (2014) Overview of the functional virulent genome of the coffee leaf rust pathogen Hemileia vastatrix with an emphasis on early stages of infection. Front. Plant Sci. 5:88. doi: $10.3389 / \mathrm{fpls.2014.00088}$

This article was submitted to Plant-Microbe Interaction, a section of the journal Frontiers in Plant Science.

Copyright (C) 2014 Talhinhas, Azinheira, Vieira, Loureiro, Tavares, Batista, Morin, Petitot, Paulo, Poulain, Da Silva, Duplessis, Silva and Fernandez. This is an openaccess article distributed under the terms of the Creative Commons Attribution License (CC BY). The use, distribution or reproduction in other forums is permitted, provided the original author(s) or licensor are credited and that the original publication in this journal is cited, in accordance with accepted academic practice. No use, distribution or reproduction is permitted which does not comply with these terms. 